UNIVERSIDADE DE SÃO PAULO

INSTITUTO DE GEOCIENCIAS

\title{
MODELO GLOBAL DO CICLO BIOGEOQUÍMICO DO CARBONO-ENXOFRE
}

Cleyde Corrêa Roncaratti

Orientador: Prof. Dr. Franco Levi

DISSERTAÇÃO DE MESTRADO

Programa de Pós-Graduação em Geoquímica e Geotectônica 


\section{UNIVERSIDADE DE SĀO PAULO INSTITUTO DE GEOCIENCIAS}

\section{MODELO GLOBAL DO CICLO BIOGEOQUÍMICO DO CARBONO-ENXOFRE}

Cleyde Corrêa Roncaratti

Orientador: Prof. Dr. Franco Levi

DISSERTAÇÅO DE MESTRADO

COMISSÃO JULGADORA

nome

Presidente: Prof.Dr. Franco Levi

Examinadores: Prof.Dr. Raphael Hypólito

Prof.Dr. Carlos Henrique de Mesquita

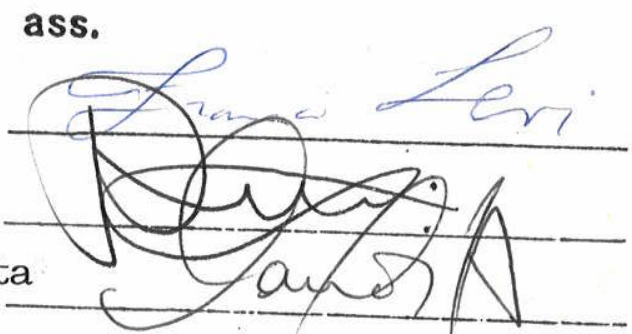


UNIVERSIDADE DE SÃO PAULO

INSTITUTO DE GEOCIENCIAS

DEDALUS - Acervo - IGC

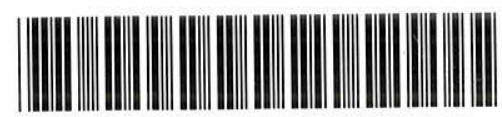

30900005492

\section{MODELO GLOBAL DO CICLO BIOGEOQUÍMICO DO CARBONO-ENXOFRE}

Cleyde Corrêa Roncaratti

Orientador: Prof. Dr. Franco Levi

DISSERTAÇÃO DE MESTRADO

Programa de Pós-Graduação em Geoquímica e Geotectônica

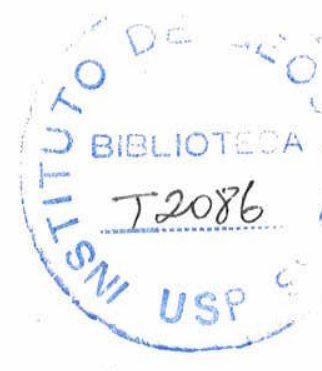

São Paulo

1995 
Para minha filha Luciana e aos meus sobrinhos Nelson, Pedro e Marcela. 


\section{Agradecimentos}

Ao Dr.Franco Levi pelo incentivo, amizade e orientação deste trabalho.

Ao Dr.Arlei Benedito Macedo por suas sugestões e análise do modelo estudado.

Ao Dr.Gilberto Amaral pela sua colaboração na parte de linguagem e programação

Ao Dr.Adilson Carvalho pelo apoio moral durante todo o trabalho .

Às professoras Dra.Thais Borges César e Telma Cortes Quadros Andrade pelas discussões e amizade dedicada.

Aos amigos pelo espírito de colaboração, aos colegas pelos momentos de descontração e a todas as pessoas que participaram direta ou indiretamente na execução desse projeto. 


\section{SUMÁRIO}

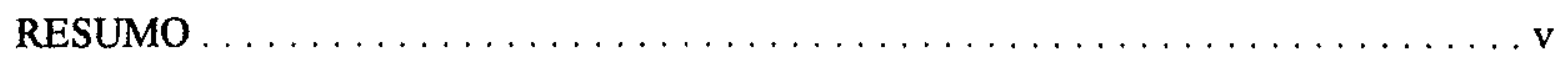
ABSTRACT $\ldots \ldots \ldots \ldots \ldots \ldots \ldots \ldots \ldots \ldots \ldots \ldots \ldots \ldots \ldots \ldots \ldots \ldots$

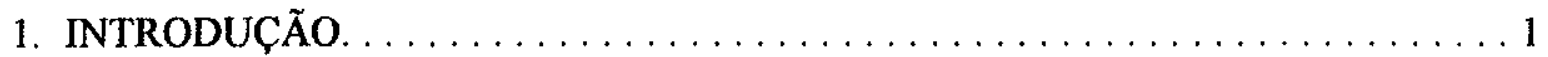

1.1.1 Ciclos globais do carbono, oxigênio e enxofre durante o Fanerozóico . . . . . . . 4

1.1.1.1 Reservatórios de carbono, oxigênio e enxofre. . . . . . . . . .9

1.1.1.2 Ciclos biogeoquímicos do carbono e do enxofre nos sedimentos . .12

1.1.2 Fracionamento isotópico no ciclo do carbono e do enxofre . . . . . . . 18

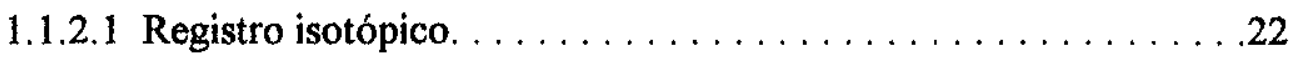

1.1 .3 Modelos globais. . . . . . . . . . . . . . . . . . . . 24

1.2.3.1 Modelo isotópico de Garrels e Lerman. . . . . . . . . . . . 26

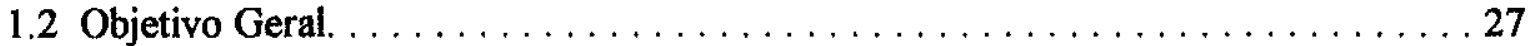

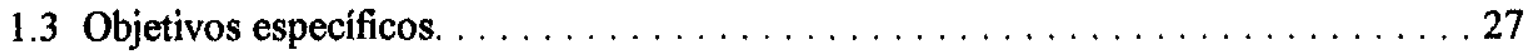

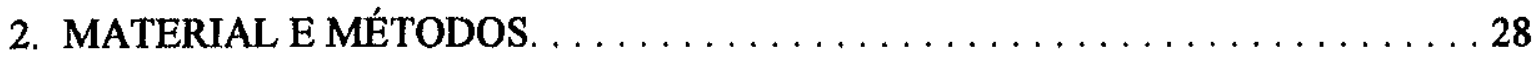

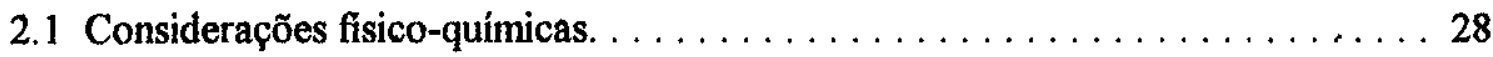

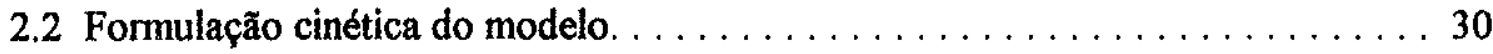

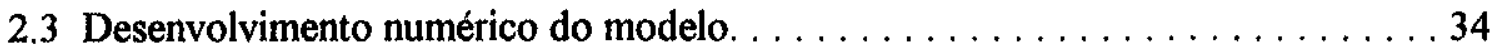

2.4 Métodos Numéricos . . . . . . . . . . . . . . . . . . . . . . . . . 39

2.4.1 Aspectos computacionais na implementação do método. . . . . . . . 41

2.4 .2 Ambiente de programação. . . . . . . . . . . . . . . 42

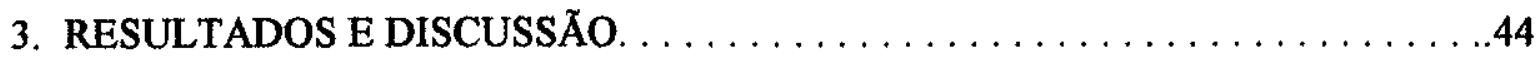

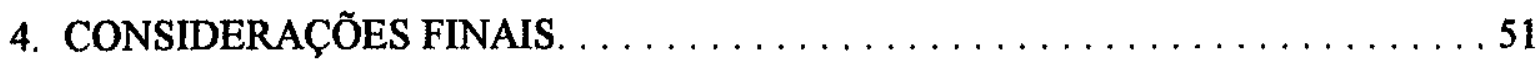

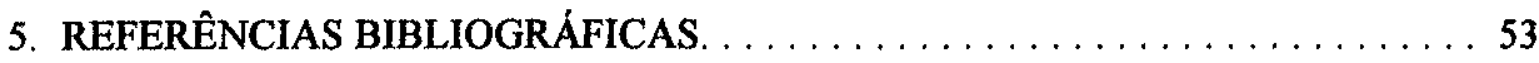

APÊNDICES 


\section{RESUMO}

Os dois ciclos mais importantes nas reações de oxi-redução, no ambiente de superficie, são o do carbono e o do enxofre que fazem parte de um sistema maior que compreende a atmosfera, biosfera e litosfera sedimentar. Levando isso em conta, partimos de um modelo de simulação numérica do ciclo biogeoquímico global, para investigar o papei do sistema carbono-oxigênio-enxofre.

A modelagem se baseia em estudos nos quais o ciclo do carbono é conjugado com o ciclo do enxofre, elaborada a partir dos principais mecanismos de oxi-redução envolvidos nos ciclos biogeoquímicos das rochas sedimentares e no registro isotópico do sulfato e carbonato marinho, durante o Fanerozóico.

A descrição numérica que compõe a estrutura do modelo se apresenta sob a forma de um sistema de Equações Diferenciais Ordinárias, empregando uma técnica de modelagem em Fortran que descreve as influências mútuas entre os diversos parâmetros geoquímicos envolvidos.

Para o intervalo de tempo considerado, os resultados se apresentam qualitativamente válidos, embora contraditórios quando se observam os teores de oxigênio atmosférico estimados.

Hipóteses mais elaboradas associadas a metodologias mais adequadas permitirão estender este estudo, possibilitando previsões mais precisas e abrangentes que conciliem de forma mais satisfatória os aspectos ambientais, tanto a nível local como regional e global. 


\section{ABSTRACT}

Carbon and sulfur cycles comprise a pair of cycles of outstanding importance when the redox processes of the atmosphere, biosphere and the sedimentary lithosphere are considered within an integrated whole. These considerations triggered in this work the development of numeric models capable of investigating the global biogeochemical within the carbon-oxigen-sulfur system.

Modeling is based on studies the carbon is considered as coupled with the sulfur cycle, in terms of the main redox mechanisms involved in the biogeochemical cycles of sedimentary rocks and in the isotopic record of marine sulfates and carbonates, during the Phanerozoic.

The model structure comprises a numerical description presented as a system of Ordinary Differential Equations, using a Fortran modeling technique that describes the mutual influences among the various geochemical variables involved.

Along the investigated time interval, results are apparently coherent, although somewhat contradictory as far as the estimated oxygen contents are concerned.

More elaborated hypotheses, associated to more adequate methodologies will allow us to extend this study in order to suggest predictions that will be both more precise and span wider intervals, including environmental aspects at the local, regional and global scales. 


\section{INTRODUÇÃO}

Paralelamente ao desenvolvimento da civilização e da tecnologia que torna possível nossa atual qualidade de vida, surge como problema do nosso tempo a contaminação ambiental, que incide no ar, água e solo. Este problema, conectado em muitos casos com a limitação dos recursos energéticos, alimentares e outros, em função da crescente demanda populacional, está dando lugar a uma revisão de critérios sociais, econômicos, técnicos e científicos.

Segundo Fyfe (1981), o ambiente de superficie global se mantém por interações entre todas as geoesferas. Tradicionalmente a Terra pode ser subdividida em "esferas": atmosfera, biosfera, hidrosfera e litosfera, onde cada uma pode ser considerada como um reservatório. No nível global, os reservatórios representam os vários componentes de um sistema cíclico, conectados de tal maneira que caracterizam as relações funcionais entre diversos processos geoquímicos envolvidos. Os maiores agentes responsáveis pelo transporte de natureza global do material de um reservatório a outro são os rios, os fluxos de água subterrânea, gelo, vento, sedimentação oceânica, transportes gasosos e outros.

A geoquímica clássica se encontra compartimentalizada desde a cosmoquímica até a geoquímica de solos e sedimentos, passando por rochas ígneas e metamórficas, incluindo aspectos específicos sobre a atmosfera, a hidrosfera e a biosfera. A integração é feita pelo ciclo geoquímico partindo de um material primordial, a matéria prima do manto terrestre que, no processo evolutivo, foi se desproporcionando para dar origem às demais geoesferas.

O conceito de natureza estrutural do ciclo geoquímico define a distribuição e migração natural dos elementos químicos na parte externa do planeta, fornecendo um referencial útil para a discussão de muitos processos geoquímicos, particularmente do curso seguido por determinados elementos químicos ao progredir por diferentes ambientes de superficie.

Há aproximadamente dois bilhões de anos, as condições reinantes na superficie da Terra flutuaram em torno de parâmetros ambientais médios, não necessariamente semelhantes aos atuais. A idéia de evolução cíclica, entre os fatores que governam essas condições de superficie global, é caracterizada por um retorno periódico de parâmetros ambientais semelhantes, no decorrer do tempo geológico (Tardy, 1987).

$O$ período Fanerozóico assinala a época na qual o teor de oxigênio atmosférico passa a ser suficientemente abundante, permitindo que os fenômenos de fotossíntese e 
respiração sejam balanceados por processos de intemperismo e deposição de carbono orgânico e enxofre nos sedimentos, mantendo constantes seus teores atmosférico e oceânico. Em escala de tempo geológico, o oxigênio atmosférico é consumido por processos de intemperismo das rochas e produzido por processos de soterramento desse material, envolvendo variações nos principais mecanismos de oxi-redução globais relacionados ao sistema oceano-atmosfera-continente.

Segundo Holland (1978), o ciclo das rochas combinado com processos biogeoquímicos, que depositam carbono e enxofre nos sedimentos, exercem os maiores controles na composição química da atmosfera e do oceano. Durante o intemperismo da rocha média na superficie, aproximadamente $60 \pm 15 \%$ de $\mathrm{O}_{2}$ é consumido pela oxidação do carbono, $30 \pm 10 \%$ pela oxidação do enxofre e $10 \pm 5 \%$ pela oxidação do $\mathrm{Fe}^{2+}$ a $\mathrm{Fe}^{3+}$. Como a biomassa não tolera grandes flutuações nos teores de $\mathrm{O}_{2}$, supõe-se que os processos de produção e consumo de oxigênio globais são balanceados, durante longos períodos, para manter o atual regime de superficie.

Com base nesses fatos, o ciclo biogeoquímico do carbono e do enxofre, sob o ponto de vista sedimentar, foi escolhido como o modelo deste projeto. As hipóteses gerais de trabalho formuladas foram (Gregor et al.,1988) :

- A massa sedimentar total, existente no passado geológico, apresenta as mesmas proporções relativas e absolutas dos seus elementos químicos individuais, observados na massa sedimentar atual (uniformitarismo).

- Os elementos químicos da massa das rochas sedimentares possuem velocidades de reciclagens diferentes da massa sedimentar total, em função dos materiais terrestre mais ou menos resistentes ao intemperismo químico e aos fenômenos de transporte (ciclagem diferencial).

Neste sentido, várias perspectivas de estudo foram abertas, sendo que uma delas se apoia em evidências isotópicas que sugerem que a conjugação de ambos os ciclos exerce importante papel na evolução biogeodinâmica global. Por outro lado, estudos por modelagem têm mostrado que o quadro geral da migração dos elementos químicos na parte externa do planeta, envolvendo de uma maneira complexa o ciclo das rochas, o ciclo da água e os ciclos tectônicos, é regulado por mecanismos cinéticos específicos que, por sua 
vez, estão sob o controle do sistema exógeno de ciclos (Lasaga, 1980). Assim, se objetivou estudar as interações geoquímicas entre os reservatórios terrestres e a sua previsibilidade fisico-química, tanto a nível qualitativo como quantitativo, sendo que os métodos numéricos permitindo estimativas sobre a relevância das diversas variáveis envolvidas. 


\subsubsection{Ciclos globais do carbono, oxigênio e enxofre durante o Fanerozóico}

Nesta seção serão focalizados, embora de modo sucinto, alguns aspectos referentes ao ciclo biogeoquímico do carbono e do enxofre, sob o ponto de vista sedimentar. $\mathrm{O}$ número de tópicos que necessitam ser abordados é vastíssimo, não só devido a complexidade do tema proposto, como também ao alto grau de especialização já atingido. Deste modo, para cada um dos tópicos aqui discutidos, serão apresentadas informações de caráter geral, absolutamente necessárias, mas sem a preocupação nem a pretensão de exaurir o tema proposto.

A quantidade total da sedimentação durante o tempo geológico é de grande importância para a geoquimica quantitativa. Atualmente a massa total das rochas sedimentares e dos íons dissolvidos no oceano é o resultado do intemperismo de rochas ígneas da crosta e a perda de seus voláteis $\left(\mathrm{H}_{2} \mathrm{O}, \mathrm{CO}_{2}, \mathrm{HCl}\right.$ e $\left.\mathrm{H}_{2} \mathrm{~S}\right)$ através do tempo geológico. Na equação abaixo, a conservação de massa total de um elemento não volátil liberado pelo intemperismo das rochas ígneas da crosta é igual à massa das rochas sedimentares acrescida da água do mar (Gregor et al. 1988):

$$
M_{i g} C_{i g}^{i}=M_{s e d} \sum A_{j} C_{j}^{i}+M_{s w} C_{s w}^{i}
$$

onde: $\quad \mathrm{M}_{\mathrm{sed}}=$ massa total das rochas sedimentares atuais estimada em torno de

$$
\begin{aligned}
& 2,5 \pm 0,4 \times 10^{24} \mathrm{~g} ; \\
\mathrm{M}_{\mathrm{ig}}= & \text { massa total das rochas ígneas na crosta intemperizada para produzir a } \\
& \text { massa sedimentar: } \mathrm{M}_{\mathrm{ig}} \text { é estimada em torno de } 0,88 \mathrm{M}_{\mathrm{sed}} ; \mathrm{M}_{\mathrm{sed}} \\
& \text { inclui elementos voláteis assim como elementos derivados } \\
& \text { do intemperismo das rochas ígneas da crosta }(\mathrm{Li}, 1972) . \\
\mathrm{M}_{\mathrm{sw}}= & \text { massa da água do mar em torno de } 1,4 \times 10^{24} \mathrm{~g} . \\
\mathrm{A}_{\mathrm{j}}= & \text { fração do tipo da rocha sedimentar (calcita, dolomita, etc.): } \sum \mathrm{A}_{\mathrm{j}}=1 ; \\
\mathrm{C}_{\mathrm{ig}}, \mathrm{C}_{\mathrm{j}} \text { e } \mathrm{C}_{\mathrm{Bw}}^{\mathrm{i}}=\text { concentração media do elemento i na rocha ígnea, na rocha } & \text { sedimentar e na água do mar. }
\end{aligned}
$$

Alexander Ronov e seus colaboradores da Academia Soviética de Ciências devotaram mais de 20 anos na compilação de mapas geológicos do mundo, estimando através de minuciosas medidas de superfice, coberta por rochas de diferentes idades, o 
volume de alguns sistemas Fanerozóicos sedimentares. O exame das flutuações da quantidade de rochas depositadas durante um determinado periodo revela que a abundância ou a ausência, em uma determinada época de depósitos sedimentares, característicos de certos paleoambientes, dependem de vários fatores geodinâmicos interdependentes como o clima, a atividade tectônica global, a forma e a posição dos continentes, a temperatura superficial média, o escoamento continental global e o teor de $\mathrm{CO}_{2}$.

Para se representar as flutuaçóes que afetam os ciclos do carbono e do enxofre durante o Fanerozóico, a superficie da terra pode ser, teoricamente, dividida em dez reservatórios, entre os quais ocorrem as transferencias materiais. Conforme a Figura (1) supõe-se que, durante 600 milhões de anos os teores do oceano e da atmosfera permaneceram constante, assim como a massa total de cada um dos elementos químicos envolvidos nos oito reservatórios sedimentares $\left(\mathrm{CaSO}_{4}, \mathrm{CaCO}_{3}, \mathrm{MgCO}_{3}, \mathrm{MgSiO}_{2}, \mathrm{SiO}_{2}\right.$, $\mathrm{FeS}_{2}, \mathrm{Fe}_{2} \mathrm{O}_{3}$ e $\mathrm{CH}_{2} \mathrm{O}$ ).

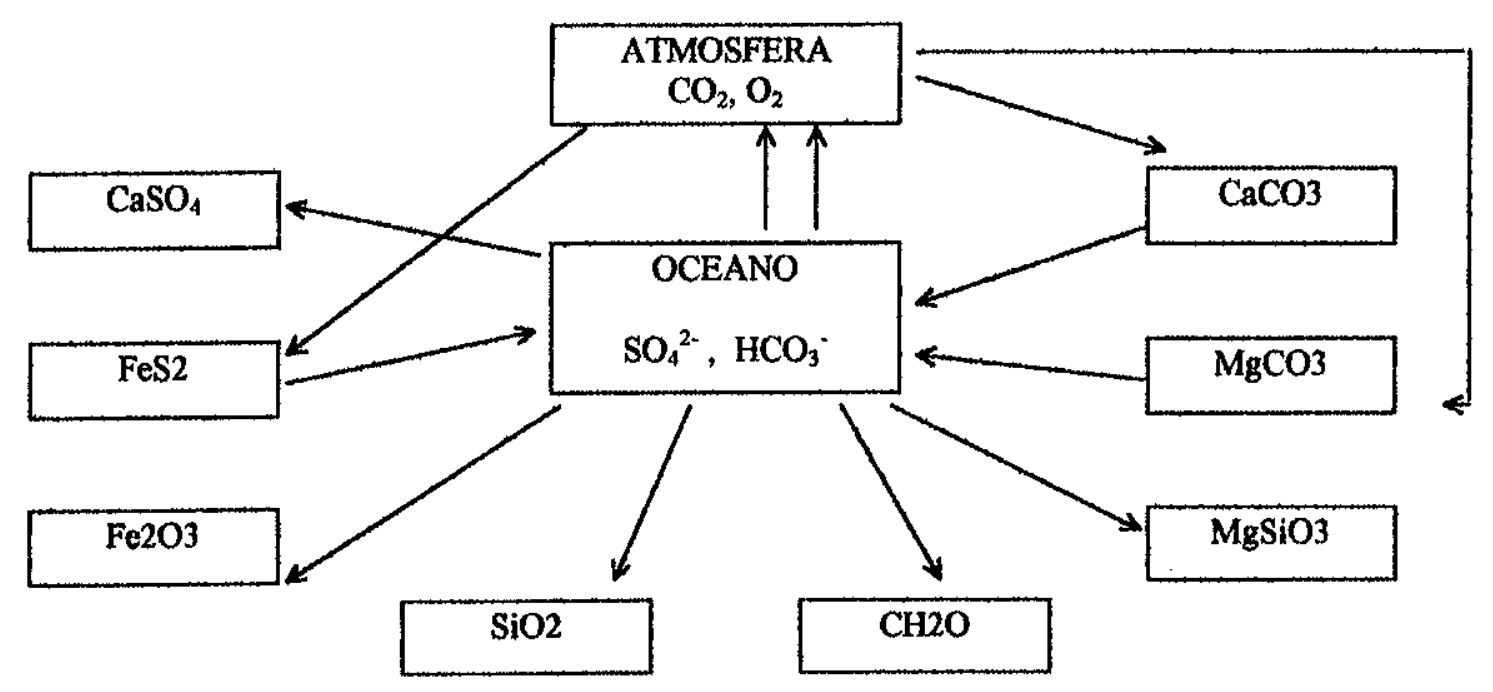

Fig.1 Diagrama de representação dos diferentes reservatórios sedimentares supondo a composição da atmosfera e dos oceanos constante (Garrels e Lerman, 1984).

A evaporação total ou parcial de águas continentais ou marinhas produz evaporitos que são quantitativamente desprovidos de importância como sedimentos, mas altamente significativos na interpretação da historia geológica. Quando a água do mar se evapora em condições naturais, o carbonato de cálcio $\left(\mathrm{CaCO}_{3}\right)$ é o primeiro solido a separar-se, seguido do sulfato de cálcio $\left(\mathrm{CaSO}_{4}\right)$ que, dependendo da temperatura e salinidade pode formar gipso ou anidrita. 
A maioria dos depósitos de evaporitos contém carbonato de cálcio, sulfato de cálcio e cloreto de sódio. Cada vez que um mol de anidrita se deposita, há a remoção de $1 \mathrm{~mol}$ de cálcio e 1 mol de sulfato do oceano, sendo necessário manter essa "alimentação" para que as quantidades totais permaneçam constantes. Pela Figura (1), observa-se um aumento nos teores do reservatório de evaporitos sedimentares de 8 moles de $\mathrm{CaSO}_{4}$ que ocorre por precipitação de gipso a partir dos ions dissolvidos nos oceanos, obedecendo à seguinte reação :

$$
2 \mathrm{H}_{2} \mathrm{O}_{(\mathrm{l})}+8 \mathrm{Ca}^{2+}{ }_{(\mathrm{aq})}+8 \mathrm{SO}_{4}{ }^{2-}(\mathrm{aq}) \leftrightarrow 8 \mathrm{CaSO}_{4} \cdot 2 \mathrm{H}_{2} \mathrm{O}_{(\mathrm{s})}
$$

Para que a composição dos oceanos se mantenha constante compensando a perda de 8 moles de $\mathrm{Ca}^{2+}$ precipitado como gipso, é necessário o fornecimento de 8 moles de $\mathrm{Ca}^{2+}$ do reservatório de carbonatos sedimentares, segundo a reação de dissolução:

$$
8 \mathrm{CaCO}_{3}+8 \mathrm{CO}_{2}+8 \mathrm{H}_{2} \mathrm{O} \leftrightarrow 8 \mathrm{Ca}^{2+}+16 \mathrm{HCO}_{3}
$$

A dissolução de 8 moles de calcita $\left(\mathrm{CaCO}_{3}\right)$ dos reservatórios das rochas sedimentares, consome 8 moles de $\mathrm{CO}_{2}$ retirado da atmosfera, liberando 16 moles de hidrogenocarbonato $\left(\mathrm{HCO}_{3}{ }^{\circ}\right)$ e 16 moles de cálcio que retornam aos oceanos pelos rios compensando a precipitação de sulfato. Todas as rochas formadas em meio marinho redutor contém enxofre reduzido, imobilizado sob forma de sulfeto de ferro transformado posteriormente em pirita ( $\mathrm{FeS}_{2}$.). A reação de oxidação e dissolução da pirita é dada por :

$$
4 \mathrm{FeS}_{2}+15 \mathrm{O}_{2} \leftrightarrow 2 \mathrm{Fe}_{2} \mathrm{O}_{3}+8 \mathrm{SO}_{4}{ }^{2-}+16 \mathrm{H}^{+}
$$

$O$ consumo de 15 moles de oxigênio retirado da atmosfera libera prótons $\mathrm{H}^{+}$, formando assim, a hematita $\left(\mathrm{Fe}_{2} \mathrm{O}_{3}\right.$ ) representada esquematicamente como sedimentos detríticos, liberando também nas águas do oceano, os 8 moles de sulfato $\left(\mathrm{SO}_{4}{ }^{2}\right.$ ) requeridos para compensar a precipitação de anidrita e estabelecendo o balanço do massa do enxofre.

A reaçăo da oxidação de 4 moles de pirita libera uma quantidade considerável de prótons $\left(16 \mathrm{H}^{+}\right)$destinada aos oceanos. Esses prótons reagem com íons bicarbonato $\left(\mathrm{HCO}_{3}{ }^{-}\right)$liberando gás carbônico que retorna a atmosfera segundo a reação : 


$$
16 \mathrm{HCO}_{3}^{-}+16 \mathrm{H}^{+} \leftrightarrow 16 \mathrm{CO}_{2}+16 \mathrm{H}_{2} \mathrm{O}
$$

$\mathrm{Na}$ natureza o sistema tampão mais importante, que freqüentemente exerce uma função reguladora do $\mathrm{pH}$ nos sistemas naturais, é formado por dióxido de carbonobicarbonato-carbonato. Se, por exemplo, existe um aporte ácido, a partir de alguma atividade vulcânica, o pH oceânico tende a diminuir levando ao consumo de carbonato $\left(\mathrm{CO}_{3}{ }^{2-}\right)$ proveniente dos sedimentos. Analogamente, se o $\mathrm{pH}$ aumenta por algum motivo, parte do gás carbônico $\left(\mathrm{CO}_{2}\right)$ aquoso se converte em bicarbonato conforme a reação (4). Nos continentes, a calcita reage com prótons $\mathrm{H}^{+}$, liberados pela oxidação da pirita, conforme a reação :

$$
8 \mathrm{CaCO}_{3}+16 \mathrm{H}^{+} \leftrightarrow 8 \mathrm{Ca}^{2+}+8 \mathrm{CO}_{2}+8 \mathrm{H}_{2} \mathrm{O}
$$

A dissolução de calcita e a oxidação de pirita liberam para a atmosfera 8 moles de gás carbônico $\left(\mathrm{CO}_{2}\right)$ cujo balanço de massa global é, em parte, assegurado pela formação da matéria orgânica representada por hidratos de carbono $\left(\mathrm{CH}_{2} \mathrm{O}\right)$ :

$$
15 \mathrm{CO}_{2}+15 \mathrm{H}_{2} \mathrm{O} \leftrightarrow 15 \mathrm{CH}_{2} \mathrm{O}+15 \mathrm{O}_{2}
$$

Os 15 moles de oxigênio, liberados pela fotossintese, são utilizados para oxidar a pirita de modo que o balanço do oxigênio é estabelecido. Aos 15 moles de matéria orgânica formada correspondem 15 moles de gás carbônico consumido pela respiração. A dissolução da calcita e oxidação da pirita liberam 8 moles de gás carbônico, faltando 7 moles que são fornecidos pela transformação do carbonato de magnésio $\left(\mathrm{MgCO}_{3}\right)$ em silicato de magnésio $\left(\mathrm{MgSiO}_{3}\right)$, dada pelas reações de silicificação e descarbonatação do magnésio segundo:

$$
7 \mathrm{MgCO}_{3}+7 \mathrm{SiO}_{2} \leftrightarrow 7 \mathrm{MgSiO}_{3}+7 \mathrm{CO}_{2}
$$

Onde, $\mathrm{MgCO}_{3}$, representa não o carbonato de magnésio no estado puro que na natureza é muito raro, mais metade da dolomita $\left(\mathrm{MgCa}\left(\mathrm{CO}_{3}\right)_{2}\right) . \mathrm{MgSiO}_{3}$ representa as argilas estáveis em condiçōes de superficie. A alteração ou dissolução dos carbonatos de magnésio, acompanhado da formação de argilas libera os 7 moles de gás carbônico complementares, mantendo o balanço de massa. 
Segundo Garrels e Perry (1974), durante o período Fanerozóico, o nível de oxigênio atmosférico deve ter permanecido constante, de modo que os fenômenos de produção e consumo de oxigênio se mantém balanceados e podem ser descritos por processos biogeoquímicos globais, relacionados ao ciclo do carbono conjugado com o ciclo do enxofre, de acordo com a reação:

$$
\begin{array}{r}
4 \mathrm{FeS}_{2}+7 \mathrm{MgCa}\left(\mathrm{CO}_{3}\right)_{2}+\mathrm{CaCO}_{3}+7 \mathrm{SiO}_{2}+15 \mathrm{H}_{2} \mathrm{O} \rightarrow \\
15 \mathrm{CH}_{2} \mathrm{O}+8 \mathrm{CaSO}_{4}+7 \mathrm{MgSiO}_{3}+2 \mathrm{Fe}_{2} \mathrm{O}_{3}
\end{array}
$$

Nas rochas sedimentares o teor dos reservatórios de anidrita $\left(\mathrm{CaSO}_{4}\right)$ aumenta enquanto o reservatório de calcita $\left(\mathrm{CaCO}_{3}\right)$ e de pirita $\left(\mathrm{FeS}_{2}\right)$ diminui, por fornecer cálcio e enxofre ao sulfato. A oxidação da pirita se faz com consumo de oxigênio aumentando a biomassa $\left(\mathrm{CH}_{2} \mathrm{O}\right)$. O gás carbônico requerido pela fotossíntese é obtido pela diminuição do reservatório de dolomita $\left(\mathrm{CaMg}\left(\mathrm{CO}_{3}\right)_{2}\right)$ e de calcita $\left(\mathrm{CaCO}_{3}\right)$ com um aumento das argilas.

Sendo assim, uma flutuação em qualquer um dos 8 reservatórios sedimentares representados pela Figura (1) deve afetar o teor de todos os outros reservatórios. Segundo a reação (8) um aumento de 8 unidades molares de $\mathrm{CaSO}_{4}$ se traduz obrigatoriamente por um aumento da biomassa de 15 unidades molares de $\mathrm{CH}_{2} \mathrm{O}$ mantendo constante a composição atmosférica e oceânica durante longos períodos de tempo. 


\subsubsection{Reservatórios de carbono, oxigênio e enxofre.}

De uma maneira geral, os reservatórios globais do ciclo biogeoquímico envolvem considerações sobre fenômenos reais, simplificados para grandes escalas e elaborados para direcionar as transferências de carbono, oxigênio e enxofre dentro do sistema oceanoatmosfera-continente. As quantidades nos diferentes reservatórios globais, medidos em $10^{18}$ moles, são mostrados na tabela (I).

\section{TABELA I}

Teor dos diferentes reservatórios de carbono, oxigênio e enxofre na superfície da Terra em $10^{18}$ moles. (Tardy, 1986).

\begin{tabular}{|c|c|}
\hline Reservatórios Globais & $10^{18}$ moles \\
\hline \multicolumn{2}{|l|}{ Carbono } \\
\hline C na biomassa & 0,006 \\
\hline C material orgânico fóssil & 1.300 \\
\hline C do gás carbônico atmosférico & 0,0550 \\
\hline $\mathrm{C}$ dos íons $\mathrm{HCO}_{3}{ }^{\circ}$ nos oceanos & 3,3 \\
\hline C na calcita dos sedimentos & 3.200 \\
\hline C na dolomita dos sedimentos & 2.000 \\
\hline $\mathrm{C}$ sob a forma de $\mathrm{CaCO}_{3}$ & 4.200 \\
\hline $\mathrm{C}$ sob a forma de $\mathrm{MgCO}_{3}$ & 1.000 \\
\hline $\mathrm{C}$ total & 6.500 \\
\hline $\mathrm{C}$ total mineral $\left(\mathrm{CO}_{3}{ }^{2-}\right)$ & 5.200 \\
\hline Corgânico total & 1.300 \\
\hline \multicolumn{2}{|l|}{ Enxofre } \\
\hline $\mathrm{S}$ nos ions $\mathrm{SO}_{4}{ }^{2-}$ dos oceanos & 42 \\
\hline S na pirita dos sedimentos & 200 \\
\hline $\mathrm{S} \mathrm{no} \mathrm{CaSO}_{4}$ dos evaporitos & 200 \\
\hline$S$ total & 442 \\
\hline \multicolumn{2}{|l|}{ Oxigênio } \\
\hline $\mathrm{O}_{2}$ na atmosfera & 38 \\
\hline $\mathrm{O}_{2}$ nos íons $\mathrm{SO}_{4}{ }^{2-}$ nos oceanos & 84 \\
\hline $\mathrm{O}_{2}$ no $\mathrm{CaSO}_{4}$ dos evaporitos & 400 \\
\hline $\mathrm{O}_{2}$ no $\mathrm{Fe}_{2} \mathrm{O}_{3}$ correspondente & 91 \\
\hline $\mathrm{O}_{2}$ total & 613 \\
\hline $\mathrm{O}_{2}$ necessário a oxidação de $\mathrm{FeS}_{2}$ & 375 \\
\hline $\mathrm{O}_{2}$ necessário a oxidação de $\mathrm{C}$ orgânico & 1.300 \\
\hline $\mathrm{O}_{2}$ demanda total de oxigênio & 1.675 \\
\hline
\end{tabular}

Como explicitado na Tabela (I), para o carbono o maior reservatório é o do carbonato, onde $2,0 \times 10^{21}$ moles estão sob a forma de dolomita e $3,2 \times 10^{21}$ moles sob a 
forma de calcita. Para o enxofre, os maiores reservatórios são os de sulfetos e sulfatos sedimentares nos evaporitos seguido do reservatório de sulfato dissolvido nos oceanos. Para o oxigênio, os maiores reservatórios são os evaporitos sedimentares e o sulfato dissolvido nos oceanos.

Comparando os teores dos diferentes reservatórios, podemos constatar que a quantidade de carbono orgânico, $\left(1,3 \times 10^{21}\right.$ moles de $\left.\mathrm{CH}_{2} \mathrm{O}\right)$ é muito maior que a quantidade de oxigênio retido nos sulfatos $\left(0,4 \times 10^{21}\right.$ moles $)$ e óxidos de ferro $\left(\mathrm{Fe}_{2} \mathrm{O}_{3}\right)$, resultante da oxidação da pirita. Considerando que, $242 \times 10^{18}$ moles de sulfato (oceanos + evaporitos sedimentares) provenientes da oxidação de $121 \times 10^{18}$ moles de pirita, com consumo de $453,75 \times 10^{18}$ moles de oxigênio, o balanceamento dos coeficientes da reação é:

$$
121 \mathrm{FeS}_{2}+453,75 \mathrm{O}_{2}+242 \mathrm{CaCO}_{3} \rightarrow 60,5 \mathrm{Fe}_{2} \mathrm{O}_{3}+242 \mathrm{CaSO}_{4}+242 \mathrm{CO}_{2}
$$

Uma certa quantidade de oxigênio é portanto retida de maneira reversível na atmosfera, pelos sulfatos e a hematita correspondente $\left(613 \times 10^{18}\right.$ moles $)$. A oxidação de $1,3 \times 10^{21}$ moles de carbono orgânico $\left(\mathrm{CH}_{2} \mathrm{O}\right)$ requer também $1,3 \times 10^{21}$ moles de oxigênio. Sendo assim, a oxidação de $100 \times 10^{18}$ moles de $\mathrm{FeS}_{2}$ requer $375 \times 10^{18}$ moles de oxigênio. A demanda total em $\mathrm{O}_{2}$ é superior a quantidade de oxigênio disponível na atmosfera $\left(38 \times 10^{18}\right.$ moles) que se mantém pela diferença entre os fluxos de oxidação dos sedimentos pirita e carbono conjugados, que subtraem oxigênio, e pelo acréscimo devido à fotossíntese.

A evolução da superficie, considerando a perda de hidrogênio na atmosfera superior, passou gradativamente de um estado reduzido originalmente ao estado oxidado atual. Essa modificação causou, naturalmente, modificações na composição química como também no tipo de reatividade química da biosfera. Durante o processo evolutivo da atmosfera, na medida que o hidrogênio foi diminuindo, a quantidade de metano também foi diminuindo, dando lugar ao aparecimento de outros compostos de carbono dentre eles o gás carbônico. À medida que a biosfera tornou-se menos redutora, seu teor de dióxido de carbono foi aumentando tanto na atmosfera quanto no oceano onde este gás é razoavelmente solúvel, em função do $\mathrm{pH}$ fracamente alcalino. A partir de certas condições ambientais, por reação deste gás os íons $\mathrm{Ca}^{2+}$ existentes em solução nos oceanos tendem a um equilíbrio de modo que a sua abundância passa a ser quase constante e igual a atual. Estas reações conduzem a precipitações de carbonatos cujas abundâncias na natureza testemunham a produção de gás carbônico através do tempo geológico acompanhando uma bem mais lenta adição vulcanica. 
O processo de transformação oxidativa do carbono deve ter ocorrido essencialmente na atmosfera, num passado longinquo, onde deve ter sido relativamente abundante pelo menos na forma de metano, gás carbônico e eventualmente monóxido de carbono. Esse processo poderia ter ocorrido também nos oceanos, embora não tão significativamente quanto na atmosfera, uma vez que os compostos de carbono são relativamente poucos solúveis em água. Poderia ainda ter ocorrido nas interface crosta-oceano, crosta-atmosfera e oceano atmosfera.

Sob o ponto de vista biogeoquímico, dois cenários evolutivos se distinguem. $\mathrm{O}$ primeiro utiliza gás metano e gás carbônico diretamente disponíveis na atmosfera. Quando o teor de metano diminui por redução do gás carbônico ou, quando o carbono do metano for incorporado pela biomassa, o potencial de oxi-redução aumenta; podendo ser possível iniciar a oxidação do ferro na pirita $\left(\mathrm{FeS}_{2}\right)$, assim como o ferro dos silicatos $\left(\mathrm{FeSiO}_{3}\right)$ e carbonatos $\left(\mathrm{FeCO}_{3}\right)$.

O segundo cenário possibilitou a síntese anaeróbia da matéria orgânica por redução de gás carbônico acompanhada da produção de sulfato de cálcio e de oxido de ferro:

$$
4 \mathrm{FeS}_{2}+7 \mathrm{CO}_{2}+\mathrm{CaCO}_{3}+15 \mathrm{H}_{2} \mathrm{O} \rightarrow \quad 15 \mathrm{CH}_{2} \mathrm{O}+8 \mathrm{CaSO}_{4}+2 \mathrm{Fe}_{2} \mathrm{O}_{3}
$$

A partir do momento que a velocidade de consumo de oxigênio por oxidação de pirita, siderita e silicatos ferro se estabiliza há uma aceleração nas reações de fotossíntese de organismos eucariontes, e o oxigênio livre aparece na atmosfera.

Portanto três condições devem ser satisfeitas, para que o oxigênio se mantenha na atmosfera: uma relação $\mathrm{CH}_{4} / \mathrm{CO}_{2}$ suficientemente baixa; uma grande produção de oxigênio por fotossíntese e uma velocidade de alteração moderada dos sulfetos, carbonatos e silicatos de ferro. 


\subsubsection{Ciclos biogeoquímicos do carbono e do enxofre nos sedimentos}

Esta seção se propõe a delinear o panorama das relações globais que ocorrem no sistema $\mathrm{C}-\mathrm{O}-\mathrm{S}$ (carbono-oxigênio-enxofre), descritos por processos geoquímicos que pertencem tanto ao ciclo do carbono quanto ao ciclo do enxofre, sob o ponto de vista sedimentar.

As principais reações de oxi-redução que envolvem o ciclo biogeoquímico das rochas são (eqs 11-14):

$$
\mathrm{CO}_{2}+\mathrm{H}_{2} \mathrm{O} \leftrightarrow \mathrm{CH}_{2} \mathrm{O}+\mathrm{O}_{2}
$$

representando a fotossíntese, onde $\mathrm{CH}_{2} \mathrm{O}$, como citado anteriormente, representa hidratos de carbono, genericamente matéria orgânica, e o seu processo inverso, a respiração. Sob o ponto de vista global, o excesso de fotossintese sobre a respiração se manifesta pela deposição e preservação da matéria orgânica nos sedimentos. Sendo assim, a proporção excedente da fotossintese preservada é função de fatores relacionados à produtividade biológica e à taxa de deposição geológica que, por sua vez, constituem as maiores fontes de oxigênio atmosférico.

A formação de pirita também é uma importante fonte de oxigênio atmosférico, de acordo com a reação:

$$
2 \mathrm{Fe}_{2} \mathrm{O}_{3}+16 \mathrm{Ca}^{2+}+16 \mathrm{HCO}^{3-}+8 \mathrm{SO}_{4}^{2-} \rightarrow 4 \mathrm{FeS}_{2}+16 \mathrm{CaCO}_{3}+8 \mathrm{H}_{2} \mathrm{O}+15 \mathrm{O}_{2}
$$

onde, para cada mol de pirita depositada, 15/8 moles de oxigênio molecular são liberados para a atmosfera. Os fatores que afetam a formação de pirita são complexos e serão discutidos nesta seção.

O oxigênio atmosférico é consumido na escala de tempo geológico por processos de intemperismo. As principais reações de oxidação do carbono orgânico e da pirita nas rochas são:

$$
\begin{gathered}
\mathrm{CH}_{2} \mathrm{O}+\mathrm{O}_{2} \rightarrow \mathrm{CO}_{2}+\mathrm{H}_{2} \mathrm{O} \\
4 \mathrm{FeS}_{2}+16 \mathrm{CaCO}_{3}+8 \mathrm{H}_{2} \mathrm{O}+15 \mathrm{O}_{2} \rightarrow 2 \mathrm{Fe}_{2} \mathrm{O}_{3}+16 \mathrm{Ca}^{2+}+16 \mathrm{HCO}_{3}+8 \mathrm{SO}_{4}{ }^{2-}
\end{gathered}
$$


Nas reações (13) e (14), onde $\mathrm{CH}_{2} \mathrm{O}$ representa aqui querogênio ou carbono fóssil, demonstra-se que a redução de carbono oxidado a carbono orgânico deve ser acompanhada pela oxidação de pirita a gipso. Sendo assim, o carbono é transferido do reservatório de carbono oxidado nos carbonatos, para o reservatório de carbono orgânico nas argilas, enquanto que o enxofre se move do reservatório de pirita ao reservatório de sulfato oxidado nos evaporitos.

A matéria orgânica encontrada atualmente nos sedimentos é o resultado de interações complexas entre a crosta e a biosfera. É possível se estimar a quantidade de carbono orgânico soterrado em sedimentos marinhos pelo conhecimento do material em suspensão carregado pelos principais rios e pelo conteúdo de carbono orgânico encontrado nos sedimentos das plataformas deltaicas. Os aspectos quantitativos assim como os fluxos de material relacionados ao ciclo biogeoquímico do carbono são apresentados na Tabela II.

TABELA II

Dados quantitativos do ciclo biogeoquímico do carbono (Berner - 1989)

\begin{tabular}{|c|c|}
\hline L.Teores & $10^{18} \mathrm{gC}$ \\
\hline Carbonato nas rochas & 60,000 \\
\hline Carbono orgânico nas rochas & 15.000 \\
\hline $\mathrm{HCO}_{3}^{-}+\mathrm{CO}_{3}^{2-}$ nos oceanos & 42 \\
\hline Decomposição na superficie & 4.0 \\
\hline $\mathrm{CO}_{2}$ atmosférico & 0,72 \\
\hline Biosfera terrestre & 0,56 \\
\hline Biosfera marinha & 0,007 \\
\hline IL.Fluxos & $10^{1 \mathrm{~g}} \mathrm{~g}$ C/ano \\
\hline Produção primária terrestre & 48 \\
\hline Produção primária marinha & 35 \\
\hline Transporte de carbono orgânico por rios para o mar & 0,40 \\
\hline Soterramento de carbono orgânico em sedimentos marinhos & 0,13 \\
\hline
\end{tabular}

Observa-se que, apesar da massa dos organismos marinhos ser menor do que a encontrada nos solos, sua produção primária é da mesma ordem de grandeza. Além do mais, a biomassa derivada dos continentes deve estar submetida a uma considerável decomposição biológica em ambientes marinhos, demonstrando um balanço entre produção e oxidação da matéria orgânica. Portanto, os fatores que afetam este parâmetro merecem uma discussão detalhada. 
A matéria orgânica se decompõe em águas naturais pela ação de microorganismos na interface água-sedimento, sendo efetuada quase que inteiramente por respiração aeróbica durante o processo de soterramento.

As principais etapas de redução seguem uma sequêencia estabelecida pela quantidade de energia livre, dada pela Tabela III, demonstrando que quando todo $\mathrm{O}_{2}$ é consumido, os processo de denitrificação e redução de manganês são efetuados, seguidos pela redução do ferro e do sulfato.

TABELA III

Processos e reações de decomposição (oxidação) da matéria orgânica na natureza (Berner - 1989)

\begin{tabular}{|c|c|}
\hline Processos e reaçōes & $\begin{array}{l}\text { Energia livre } \\
\text { padräo } \Delta \mathrm{G}^{0} \\
\mathrm{~kJ} / \mathrm{mol}^{2} \mathrm{CH}_{2} \mathrm{O}\end{array}$ \\
\hline Respiração aeróbica & \\
\hline $\begin{array}{l}\mathrm{CH}_{2} \mathrm{O}+\mathrm{O}_{2} \rightarrow \mathrm{CO}_{2}+\mathrm{H}_{2} \mathrm{O} \\
\text { Denitrificaçăo }\end{array}$ & -475 \\
\hline $\begin{array}{l}5 \mathrm{CH}_{2} \mathrm{O}+4 \mathrm{NO}_{3}^{-} \rightarrow 2 \mathrm{~N}_{2}+4 \mathrm{HCO}_{3}^{-}+\mathrm{CO}_{2}+3 \mathrm{H}_{2} \mathrm{O} \\
\text { Redução de Manganês }\end{array}$ & -448 \\
\hline $\begin{array}{l}\mathrm{CH}_{2} \mathrm{O}+3 \mathrm{CO}_{2}+\mathrm{H}_{2} \mathrm{O}+2 \mathrm{MnO}_{2} \rightarrow 2 \mathrm{Mn}^{2+}+4 \mathrm{HCO}_{3}^{-} \\
\text {Reduçao de ferro }\end{array}$ & -349 \\
\hline $\begin{array}{l}\mathrm{CH}_{2} \mathrm{O}+7 \mathrm{CO}_{2}+4 \mathrm{Fe}(\mathrm{OH})_{3} \rightarrow 4 \mathrm{Fe}^{2+}+8 \mathrm{HCO}_{3}{ }^{2-}+3 \mathrm{H}_{2} \mathrm{O} \\
\text { Reducto de sulfato }\end{array}$ & .114 \\
\hline $\begin{array}{l}2 \mathrm{CH}_{2} \mathrm{O}+\mathrm{SO}_{4}^{2-} \rightarrow \mathrm{H}_{2} \mathrm{~S}+2 \mathrm{HCO}_{3}^{-} \\
\text {Metanogênese }\end{array}$ & -77 \\
\hline $2 \mathrm{CH}_{2} \mathrm{O} \rightarrow \mathrm{CH}_{4}+\mathrm{CO}_{2}$ & -58 \\
\hline
\end{tabular}

Recentemente, Berner (1989b) demonstrou que a redução do ferro precede a redução do sulfato e continua até que todo o oxigênio dissolvido seja consumido, dando lugar aos processos de metanogênese. A biomassa passa por oxidação e redução simultânea resultando em pouca energia livre para a utilização por bactérias, o carbono orgânico é assim soterrado.

Neste trabalho serão enfatizados os processos de decomposição por oxigênio e sulfato por serem os principais oxidantes da matéria orgânica. Os mecanismos de denitrificação não serão considerados por serem limitados pelos baixos teores de íns nitrato $\left(\mathrm{NO}_{3}{ }^{-}\right)$na água do mar.

Através de dados experimentais, Berner (1982) sugeriu que a velocidade de decomposição da matéria orgânica sedimentar pode ser caracterizada por uma expressão cinética de primeira ordem dada por: 
$\mathrm{dG}_{\mathrm{i}}=-\mathrm{k}_{\mathrm{i}} \cdot \mathrm{G}_{\mathrm{i}}$

$\mathrm{dt}$

$\mathrm{G}_{\mathrm{t}}=\sum \mathrm{G}_{\mathrm{i}}$

$\underline{\mathrm{dG}_{\mathrm{t}}}=-\sum \mathrm{k}_{\mathrm{i}} \mathrm{G}_{\mathrm{i}}$

$\mathrm{d} t$

onde:

$\mathrm{i}=$ população de planctons

$\mathrm{G}_{\mathrm{i}}=$ concentração de carbono orgânico por grupo de reatividade $i$

$k_{i}=$ constante de decomposição por grupo de reatividade $i$

$\mathrm{G}_{\mathrm{t}}=$ concentração total de $\mathrm{C}$ orgânico

$\mathrm{t}=$ tempo

Nestes estudos foram determinados alguns valores das constantes cinéticas de decomposição $\left(k_{i}\right)$, que diminuem com a profundidade, através de uma correlação linear positiva entre a velocidade de redução do sulfato e a velocidade de decomposição do carbono orgânico em concordância com a equação (15). Assim, para uma dada deposição orgânica, a velocidade de soterramento irá depender não somente da velocidade de decomposição mas também do tempo necessário para que esse material seja processado.

Muitos estudos foram feitos no sentido de se quantificar o fluxo mundial de carbono orgânico soterrado no passado geológico, por exemplo: Garrels e Perry, 1974; Holland, 1978; Lasaga, 1981; Berner, 1982. Os aspectos quantitativos sobre as velocidades de deposição de matéria orgânica em diferentes tipos de sedimentos marinhos são apresentados na Tab. IV.

TABELA IV

Velocidades de soterramento da matéria orgânica em diferentes sedimentos (Berner - 1989)

\section{Tipos de sedimentos}

Sedimentos de plataformas deltaicas

Sedimentos orgânicos de regióes de alta produtividade

Sedimentos carbonáticos de águas rasas

Sedimentos pelágicos

Bacias redutoras

Velocidades de carbono orgânico soterrado $10^{h 2}$ e/ano 
O ciclo biogeoquimico do enxofre nos sedimentos é inseparável do ciclo do carbono. Os principais mecanismos de redução do sulfato só podem ocorrer na presença da matéria orgânica por um conjunto apropriado de bactérias que, por sua vez, são responsáveis pela formação de pirita, enfatizando os processos que resultam no material preservado no registro geológico. As interações entre basalto e água do mar não serão consideradas nestes estudos.

O primeiro passo na formação de pirita sedimentar, envolve a redução simultânea do sulfato dissolvido e a oxidação da matéria orgânica, mediada por bactérias e outros microorganismos anaeróbicos dada por :

$$
\mathrm{CH}_{2} \mathrm{O}+\mathrm{SO}_{4}{ }^{2-} \rightarrow \mathrm{H}_{2} \mathrm{~S}+2 \mathrm{HCO}_{3}^{-}
$$

A velocidade de redução do sulfato nos sedimentos está em função de uma variedade de parâmetros sendo que o mais importante, considerado aqui, é dado pela reatividade da matéria orgânica, expressa pela constante cinética de primeira ordem $\mathrm{k}_{1}$, conforme já discutido.

A abundância do sulfato dissolvido na água do mar, e a sua velocidade de redução em relação à profundidade, mostrada no perfil da Figura (2), sugere a existência de outros mecanismos de oxi-redução envolvidos nos processos geoquímicos, dependentes de uma maneira geral da matéria orgânica, dos teores de sulfato e de minerais contendo ferro. $\mathbf{O}$ gás sulfidrico $\left(\mathrm{H}_{2} \mathrm{~S}\right)$ produzido pela redução do sulfato na camada superficial ( $\cong 20 \mathrm{~cm}$ ) migra para os sedimentos, onde uma parte é novamente oxidado por fenômenos de turbulência enquanto que o material remanescente poderá eventualmente reagir com minerais detríticos contendo ferro transformando-se em pirita. A formação de pirita também é favorecida pela concentração de minerais contendo ferro em suspensão que são rapidamente metabolizados pela matéria orgânica nos sedimentos. 


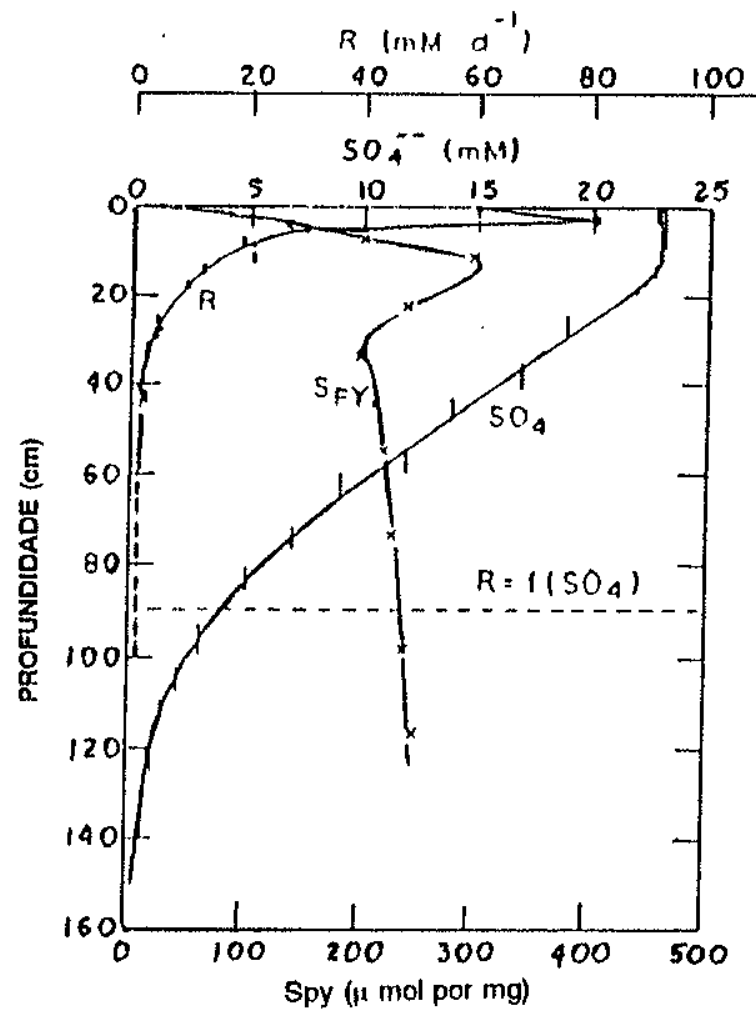

Fig. 2 -Concentração de sulfato dissolvido $\left(\mathrm{SO}_{4}\right)$, velocidade de redução de sulfato ( ) e formaçâo de pirita (Spy) versus profundidade nos sedimentos de Long Island Sound. A profundidade $R=f\left(\mathrm{SO}_{4}\right)$ representa o nivel onde os teores de sulfato dissolvido são insuficientes para se observar qualquer mecanismo (Berner, 1989).

Estes processos geoquímicos constituem o principal mecanismo de remoção do sulfato da água do mar, mantendo a concentração num estado estacionário por longos períodos. A formação de pirita também ocorre em ambientes euxínicos marinhos ou quase marinhos, extremamente pobres em oxigênio e ricos em gás sulfidrico. $O$ sedimento proveniente deste ambiente é rico em matéria orgânica. Um outro ambiente adicional, no qual a pirita sedimentar pode ocorrer, é o das águas de lagos e pântanos, limitada por baixos teores de sulfeto dos compostos orgâno-sulfurosos.

Por ser a velocidade de redução do sulfato primariamente uma função da reatividade da matéria orgânica, a preservação desse material está correlacionada de maneira positiva com a velocidade de sedimentação, enfatizando os fenômenos de deposição no ciclo biogeoquímico do carbono e no ciclo do enxofre. 


\subsubsection{Fracionamento isotópico no ciclo do carbono e do enxofre}

Neste capítulo serão abordados os principais conceitos relacionados ao fracionamento dos isótopos naturais do carbono e do enxofre no ciclo biogeoquímico e seus respectivos registros isotópicos no Fanerozóico.

Muitos constituintes que participam dos ciclos geoquímicos apresentam significante fracionamento isotópico devido à dependência de algumas de suas propriedades físicoquímicas. $\mathrm{O}$ fracionamento químico dos isótopos estáveis é o resultado das pequenas diferenças nas energias livres de formação das moléculas a partir de seus átomos constituintes.

A utilização dos isótopos baseia-se na determinação das relações ${ }^{13} \mathrm{C}^{12} \mathrm{C} \mathrm{e}{ }^{34} \mathrm{~S} /{ }^{32} \mathrm{~S}$ no material em estudo em referidas a um padrão. A compreensão destes fenômenos é importante na interpretação de dados isotópicos que, eventualmente estejam relacionados com a história do planeta.

Segundo Gregor (1988), fracionamentos isotópicos são termodinâmicamente controlados por processos de equilíbrio ou cinéticamente controlados por diferentes velocidades de reação entre substâncias químicas. No caso do carbono e do enxofre, estas características afetam principalmente as relações ${ }^{12} \mathrm{C} /{ }^{13} \mathrm{Ce}^{32} \mathrm{~S} /{ }^{34} \mathrm{~S}$.

$\mathrm{O}$ fracionamento isotópico numa reação química pode ser convenientemente expresso pelo fator de fracionamento $\mathrm{K}$ dado por :

$$
\mathrm{K}=\frac{\left({ }^{12} \mathrm{C} /{ }^{13} \mathrm{C}\right)_{\text {produtos }}}{\left({ }^{12} \mathrm{C} /{ }^{13} \mathrm{C}\right)_{\text {reagentes }}}
$$

Nos processos de equilibrio termodinâmico, $\mathrm{K}$ é dependente da constante de equilibrio, enquanto que nos processos cinéticos essa dependência é dada pelas constantes de velocidades de reação, $k_{1}$ e $k_{2}$ das espécies individuais. Para o caso do carbono temos:

$$
{ }^{12} \mathrm{C}_{\text {reagentes }} \stackrel{\mathrm{k} 1}{\longrightarrow}{ }^{12} \mathrm{C}_{\text {produtos }} ;{ }^{13} \mathrm{C}_{\text {reagentes }} \stackrel{\mathrm{k} 2}{\longrightarrow}{ }^{13} \mathrm{C}_{\text {produtos }}
$$

Se $k_{1}$ for substancialmente diferente de $k_{2}$ então, a composição isotópica dos produtos de uma reação será, necessariamente, diferente da composição isotópica dos seus regentes iniciais. 
As variações isotópicas entre as substâncias são usualmente relacionadas pela notação $\delta$ que expressa a diferença do conteúdo do isótopo menos abundante numa amostra, em partes por mil, em relação a um padrão:

$$
\delta R=\left(\frac{R_{\text {amostra }}}{R_{\text {pudrao }}}-1\right) \times 1000
$$

onde $\mathrm{R}={ }^{13} \mathrm{C} /{ }^{12} \mathrm{C}$ ou ${ }^{34} \mathrm{~S} /{ }^{32} \mathrm{~S}$

Assim, uma amostra com valor negativo significa um empobrecimento frente ao padrão, isto é, o sinal negativo indica que a razão $\mathbf{R}$ da amostra é menor que a razão $\mathbf{R}$ do padrão. Normalmente, amostras enriquecidas em ${ }^{13} \mathrm{C}$ ou ${ }^{34} \mathrm{~S}$ são denominadas "mais pesadas"; reciprocamente, amostras empobrecidas são denominadas "mais leves".

Segundo Kump e Garrels (1986), para o caso do carbono, o padrão usual é a rocha calcária da formação Peed do Grand Canyon nos Estados Unidos (PDB) $\operatorname{com}{ }^{12} \mathrm{C} /{ }^{13} \mathrm{C}$ igual a 88,99 enquanto que para o enxofre é a troilita Canyon Diablo (CDT) $\operatorname{com}^{32} \mathrm{~S} /{ }^{34} \mathrm{~S}$ igual a 22,22 .

Os processos envolvidos no ciclo geoquímico do carbono e do enxofre que envolvem fracionamentos biologicamente intermediados apresentam efeitos cinéticos que predominam em relação aos efeitos termodinâmicos.

Táo importante quanto o conhecimento da existência do fracionamento isotópico é o fato de que, em sua grande maioria, os processos fracionantes para os compostos de carbono são hoje bem conhecidos.

O mais importante fracionamento isotópico no ciclo do carbono está ligado aos processos de fixação fotossintética. A composição isotópica da principal fonte que controla o ciclo do carbono na natureza, isto é, o $\mathrm{CO}_{2}$ atmosférico, apresenta um valor aproximadamente constante, em torno de $-7 \%$ em relação ao padrão (PDB).

De um modo geral, o fracionamento isotópico existente entre a fonte de carbono atmosférico e uma planta é dividido em duas etapas: a primeira envolvendo a absorção de $\mathrm{CO}_{2}$ atmosférico por estômatos e a segunda pela conversão enzimática do $\mathrm{CO}_{2}$ dissolvido no citoplasma a carboidratos. A somatória dos fracionamentos ocorridos em cada etapa totaliza o fracionamento observado na biomassa.

As plantas são divididas em duas categorias quanto sua composição isotópica: plantas do tipo $\mathrm{C}-3$ (ciclo Calvin) que apresentam valores em tomo de -25 a $-35 \%$ 
relacionados às gimnospermas, algas e bactérias autotróficas e as plantas do tipo $\mathrm{C}-4$ com fracionamentos entre -24 a $-6 \%$, dados pelas angiospermas.

A discriminação isotópica estabelecida no ciclo do carbono por processos de equilíbrio termodinâmicos é menos pronunciada do que a dos processos cinéticos, conforme citado anteriormente. A composição isotópica das várias espécies de carbono oxidado no ciclo exógeno, especialmente no sistema:

$$
\mathrm{CO}_{2} \text { (gás) } \leftrightarrow \mathrm{CO}_{2}(\mathrm{aq}) \leftrightarrow \mathrm{HCO}_{3}^{-} \leftrightarrow \mathrm{CO}_{3}{ }^{2-}
$$

constitui as principais interações entre o gás carbônico atmosférico e o carbonato sedimentar.

A uma temperatura em torno de 0 a $30^{\circ} \mathrm{C}$, o gás carbônico dissolvido na água é enriquecido entre 1,0 e $1,2 \%$ comparado com a fase gasosa, enquanto que $o$ fracionamento entre $\mathrm{CO}_{2}$ (aq) e $\mathrm{HCO}_{3}{ }^{*}$ resulta num enriquecimento de 7 a $11 \%$ de ${ }^{13} \mathrm{C}$ no íon bicarbonato. $\mathrm{O}$ fracionamento entre bicarbonato e carbonato é menos pronunciado, causando um aumento de carbono pesado de $1 \%$ na fase carbonato.

O conhecimento deste equilíbrio termodinâmico é fundamental para uma interpretação mais conclusiva sobre antigos registros de carbono que, em geral, apresentam valores mais empobrecidos nas espécies reduzidas, e valores mais enriquecidos nas espécies oxidadas, sugerindo que os processos foram se intensificando no decorrer do tempo.

Semelhante ao ciclo do carbono, os fracionamentos isotópicos geoquímicamente mais importantes no ciclo do enxofre estão relacionados aos processos exclusivamente bioquímicos atribuídos à redução bacteriogênica de sulfato. Este processo é o principal responsável (a baixa temperatura) pela conversão de sulfato a sulfeto no sistema exógeno, descrito no capítulo anterior (seção 1.1.1.2).

Os padrões bioquímicos de redução efetuados no interior das células podem ser convenientemente sumarizados em quatro etapas:

$$
\mathrm{SO}_{4}^{2-} \text { (ext.) } \rightarrow \mathrm{SO}_{4}^{2-} \text { (int.) } \stackrel{\mathrm{ATP}}{\longrightarrow} \mathrm{APS} \stackrel{2 \mathrm{2e-}}{\longrightarrow} \mathrm{SO}_{3}{ }^{2-} \stackrel{60-}{\longrightarrow} \mathrm{S}^{2-}
$$

(2)

(3) 
Inicialmente o sulfato é capturado por organismos vivos no passo (1), metabolizado no passo (2), na presença de ATP (adenina trifosfato) produzindo assim um composto ativado (APS-adenilil sulfato) que irá favorecer a redução enzimática de sulfato a sulfito no passo (3), e a subseqüente redução a sulfeto no passo (4), como produto final da série de reações. Através de todo esse processo, o estado de oxidação do enxofre passa de +6 a -2 exigindo a transferência de 8 elétrons provenientes de um doador orgânico externo.

Os efeitos isotópicos nessas reações são de magnitude variável, podendo ser atribuídos a uma somatória das variações negativas de $\delta^{34} \mathrm{~S}$, que se apresentam em torno de $-46 \%$ em culturas experimentais, e alcançam $-60 \%$ no ambiente natural; isto é, valores de $\delta^{34} \mathrm{~S}$ de sulfeto bacteriogênico são acentuadamente deslocados para valores mais negativos cuja magnitude pode variar dependendo do passo dominante de (1) a (4), da velocidade de reação e das respectivas espécies envolvidas.

$\mathrm{O}$ único controle termodinâmicamente importante para o ciclo do enxofre na crosta é estabelecido pelo equilíbrio entre as espécies dissolvidas e precipitadas de sulfato, dado pelo fator de fracionamento K (equação 19).

$\mathrm{O}$ conhecimento sobre o fracionamento isotópico é fundamental para uma interpretação mais conclusiva sobre os antigos registros de carbono e enxofre que, em geral, apresentam valores mais empobrecidos nas espécies reduzidas e valores mais enriquecidos nas espécies oxidadas. 


\subsubsection{Registro isotópico}

Uma das melhores evidências sobre as possiveis transferências de massa entre os reservatórios sedimentares globais é fornecida pelo registro isotópico do carbono e do enxofre oceânico preservado nos evaporitos e carbonatos, respectivamente, dados pela Figura (3) (Kump e Garrels, 1986)

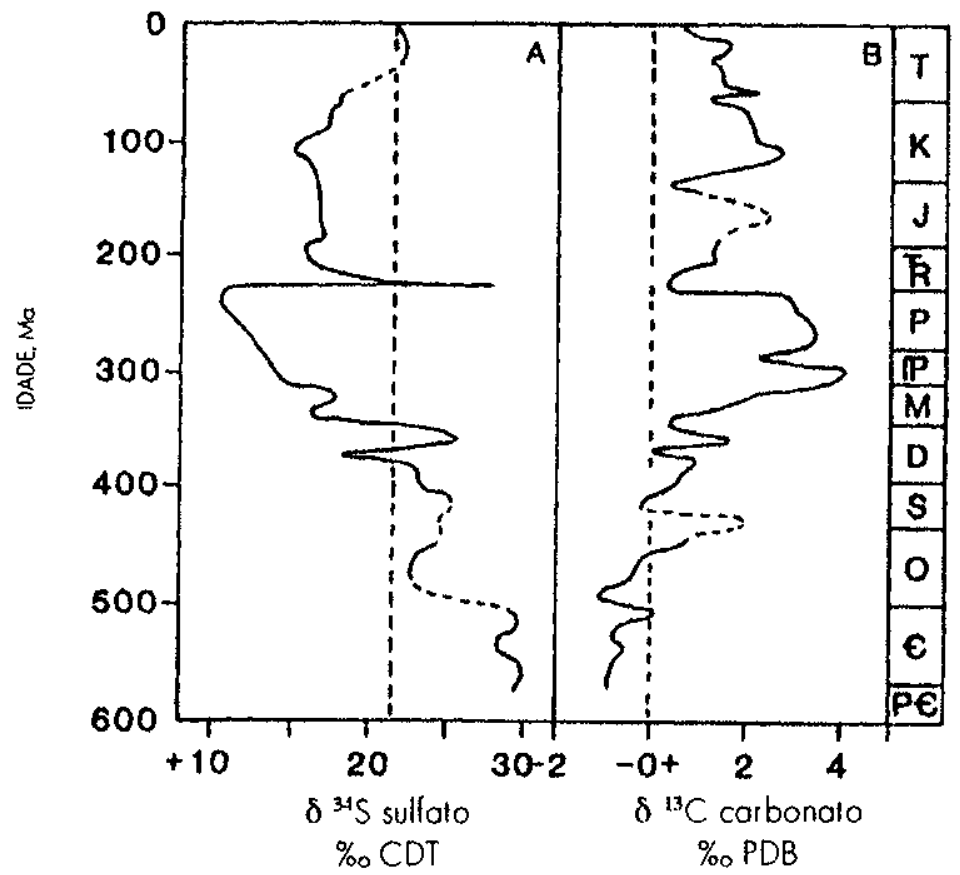

Fig.3 - Registro isotópico de sulfato e carbonato marinhos durante o Fanerozóico, em relação aos seus respectivos padrões (Kump e Garrels - 1986)

As variações de $\delta^{34} \mathrm{~S}$ nos depósitos de sulfato marinho apresentam amostras mais leves, em torno de $11 \%$ no Permiano e amostras mais pesadas no Cambriano de $30 \% \mathrm{O}$ fracionamento isotópico médio desses depósitos é calculado por volta de $21 \%$ que, por sua vez, representa um valor ligeiramente mais enriquecido em relação ao registro atual de $20 \%$. A correspondente variação em $\delta^{13} \mathrm{C}$ nos carbonatos marinhos, dada pela Figura (3B) acima, apresenta variações mais discretas nos valores dos fracionamentos registados, atribuídos ao tamanho do reservatório de carbonato comparado com o reservatório de sulfato. As amostras mais enriquecidas de $\delta^{13} \mathrm{C}$, que se apresentam em torno de $4 \%$, são registradas no Permiano e Eoceno enquanto que as amostras mais empobrecidas, próximas a $-0,8 \%$, são observadas no Ordoviciano. 
O fracionamento isotópico médio do carbonato, calculado para o período Fanerozóico, se situa em torno de $0,2 \%$ podendo distinguir dois períodos na Figura (3): um período anterior ao Carbonífero, durante o qual amostras de $\delta^{13} \mathrm{C}$ são mais empobrecidas em relação ao valor médio e, um outro período posterior que apresenta amostras mais enriquecidas. As flutuações na composição isotópica de ambos tipos de depósitos marinhos demonstram também uma certa correlação inversa entre seus respectivos valores, registrados durante o Fanerozóico.

Segundo Kump e Garrels (1986) durante o Paleozóico, o oceano foi progressivamente enriquecido em relaçao aos valores de $\delta^{13} \mathrm{C}$ devido a uma remoção preferencial de amostras mais empobrecidas de carbono orgânico, e um empobrecimento em $\delta^{34} \mathrm{~S}$ devido a remoção de amostras mais enriquecidas de sulfato de acordo com Garrels e Perry (1971).

Considerando a velocidade de soterramento de carbono e a razão entre a velocidade de soterramento do carbono e da pirita ( $\mathrm{C} / \mathrm{S}$ ) temos que, a velocidade de carbono orgânico soterrado aumenta durante o Paleozóico atingindo um valor máximo no Carbonífero e Permiano, com valores intermediários durante o Mesozóico e Cenozóico. (Figura 3) Esses valores são atribuídos a um aumento na velocidade de soterramento do carbono orgânico e diminuição na velocidade de soterramento da pirita atribuída ao aumento e expansão de plantas vasculares durante o Paleozóico (Berner, 1987 ) fornecendo uma nova fonte de detritos orgânicos nos sedimentos, após transporte pelos rios. Antes desse período, supõese que somente no ambiente marinho havia matéria orgânica disponível para esses processos.

Segundo Berner e Raiswell (1983), durante o Paleozóico as condições redutoras nos oceanos foram mais intensas em função das condições euxínicas, tendo ocorrido mais facilmente processos de decomposição da matéria orgânica por bactérias favorecendo, em maior extensão, a formação de pirita em ambiente marinho. 


\subsubsection{Modelos Globais}

Os modelos de ciclos geoquímicos apresentam relações funcionais entre os diversos fenômenos naturais, que operam em escala global durante o tempo geológico.

Resumidamente, I. Vernadsky, no inicio do século, relacionou a biosfera com os ciclos geoquimicos, podendo ser considerado como um dos fundadores da biogeoquimica. Os aspectos cíclicos foram quantificados por A. Lotka abrindo um novo campo de investigação que mostra a importância das trocas químicas nos processos globais da vida, caracterizando as raizes numéricas da ecologia global. Posteriormente, a modelagem matemática e a Teoria Geral dos Sistemas de von Bertalanffy permitiram diversos desenvolvimentos teoricos que contruibuiram para a análise inicial da assim chamada "crise ambiental".

$\mathrm{Na}$ construção de um modelo global, os fenômenos reais são simplificados por diagramas de blocos, supostamente homogêneos, esquematizados em função de suas particularidades geoquímicas e descritos por sistemas numéricos. No inicio, um dos principais trabalhos envolvendo modelagens de ciclos geoquímicos, foi desenvolvido por Holland (1973) com o objetivo de se prever a natureza das variações de oxigênio atmosférico no decorrer do Fanerozóico, através do estudo do ciclo do enxofre. Posteriormente, Garrels e Perry (1974) considerando que o conteúdo de $\mathrm{O}_{2}$ atmosférico permanece relativamente constante durante longos periodos no Fanerozóico, descreveram um sistema de reações de oxi-redução por meio do qual a perda de oxigênio demandada pela operação do ciclo do carbono é balanceada por uma equivalente perda de $\mathrm{O}_{2}$, fornecido pela operação do ciclo do enxofre.

Garrels, Lerman e Mackenzie (1976) determinaram uma série de relações funcionais entre os fluxos e reservatórios do sistema C-O-S (carbono-oxigênio-enxofre) desenvolvendo um modelo sedimentar cíclico que inclui o oxigênio e o gás carbônico atmosférico. Este modelo considera os fatores relacionados às velocidades de oxidação e redução das reações de primeira ordem entre os reservatórios sedimentares; a quantificação da massa total de carbono orgânico dada pela fotossintese e pelo material sepultado nos sedimentos; a dependência entre produção de pirita e a massa dos reservatórios oceânicos; e a manutenção da saturação do sulfato com relação a calcita.

Modelos mais detalhados sobre transferências entre $\mathrm{C}-\mathrm{O}-\mathrm{S}$ (carbono-enxofreoxigênio) foram desenvolvidos por Garrels e Lerman (1981), modificados por Berner e 
Raiswell (1983), e recalculados em um trabalho clássico por Garrels e Lerman (1984). Em seus cálculos, eles usaram a mesma transferência estequiométrica de Garrels e Perry (1974) para conjugar o ciclo do enxofre ao ciclo do carbono, produzindo um modelo numérico que estima o comportamento dinâmico integrado entre reservatórios oxidados e reduzidos de carbono e enxofre no decorrer do Fanerozóico. Os valores do fracionamento isotopico de $\delta^{13} \mathrm{C}$ e $\delta^{34} \mathrm{~S}$ registrados nos carbonatos e sulfatos oceânicos, respectivamente, são usados para o cálculo das velocidades globais de soterramento e intemperismo da matéria orgânica, do carbonato nas rochas, da pirita sedimentar e do gipso e da anidrita evaporíticos.

Utilizando a mesma estratégia de modelagem, Berner, Lasaga e Garrels (1983) construíram um modelo de evolução da temperatura para os últimos 100 milhões de anos no ciclo do carbonato-silicato a nível global (conhecido como modelo BLAG), usando um conjunto detalhado de relações de fluxos, levando em conta a taxa de expansão do assoalho oceânico, a temperatura global e área superficial, além dos efeitos destes processos nos teores de gás carbônico atmosférico. Este modelo posteriormente foi expandido para incluir outros processos (Lasaga, Berner, Garrels, 1985).

Kump e Garrels (1986), pela análise dos isótopos estáveis de carbono e enxofre, desenvolveram a modelagem do oxigênio atmosférico no ciclo sedimentar global aplicado ao Cenozóico incluindo de um reservatório de oxigênio atmosférico, em função da natureza das interações entre os subciclos do carbono e do enxofre.

Berner (1987) propôs uma extensão do modelo de Garrels e Lerman (1984) para o ciclo geoquímico conjugado de carbono, enxofre e oxigênio pela introdução de mecanismos de retroalimentação entre as formas oxidadas e reduzidas de carbono e enxofre. Este modelo é conhecido também como "modelo de reciclagem rápida".

Kump (1989) sugeriu uma modelagem alternativa para uma aproximação do ciclo geoquímico do carbono, enxofre e estrôncio (Sr) dados por seus respectivos registros isotópicos, demonstrando que, os períodos de transgressão marinha, são refletidos na contribuição isotópica por um empobrecimento de $\delta^{13} \mathrm{C}$ nas rochas carbonáticas $\mathrm{e}$ enriquecimento de $\delta^{34} \mathrm{~S}$ nos evaporitos. Analogamente, os períodos de regressão marinha apresentam um enriquecimento de $\delta^{13} \mathrm{C}$ em carbonatos e empobrecimento de $\delta^{34} \mathrm{~S}$ nos evaporitos.

Berner e Canfield (1989) desenvolveram um modelo para o oxigênio atmosférico no Fanerozóico, no qual se considera que o oxigênio atmosférico provavelmente variou 
durante o Carbonífero e o Permiano, devido primariamente ao aumento das plantas vasculares.

Em duas recentes publicações Berner (1990) e (1991), quantificou novos parâmetros do ciclo biogeoquímico do carbono possibilitando o cálculo dos teores de gás carbônico atmosférico no Fanerozóico, enfatizando os fenômenos de intemperismo das rochas e seus efeitos. Os fatores que controlam a velocidade de intemperismo incluem mudanças na área superficial e elevação média nos continentes, efeito estufa e a evolução das plantas vasculares.

Convém ressaltar que todos os modelos de ciclos geoquímicos sedimentares desenvolvidos nos últimos dez anos, são fundamentalmente derivados do modelo de Garrels e Lerman (1984).

\subsubsection{Modelo isotópico de Garrels e Lerman}

Garrels e Lerman (1984), supondo que as massas globais de carbono e enxofre no oceano, na atmosfera e nos reservatórios sedimentares de gipso, pirita, calcita e carbono orgânico permanecem relativamente constantes durante o Fanerozóico, elaboraram um modelo isotópico para o ciclo sedimentar do carbono, conjugado com o ciclo do enxofre, no qual são quantificadas as velocidades entre os reservatórios globais com base no registro isotópico dos carbonatos e sulfatos nos sedimentos marinhos. Este modelo demonstra numericamente que, os períodos durante os quais se depositam significantes quantidades de evaporitos, além de apresentarem amostras mais empobrecidas de $\delta^{34} \mathrm{~S}$ oceânico, são períodos onde se observa também, um acúmulo de carbono orgânico sedimentar, interpretando desta forma, a conjugação de ambos os ciclos. 


\subsection{Objetivo Geral}

O presente trabalho tem como objetivo central, a investigação da distribuição espacial e temporal dos constituintes do ciclo biogeoquímico do carbono e do enxofre no Fanerozóico, enfatizando os processos geoquímicos sedimentares de alguns fenômenos globais.

A análise da variabilidade dos grandes reservatórios, associada a interferências de caráter antrópico, visa indicar um possível papel seletivo do sistema carbono-oxigênioenxofre sobre o ambiente de superfice, através de mecanismos cinéticos específicos entre alguns reservatórios terrestres.

\subsection{Objetivos Especificos}

a ) Desenvolvimento e aplicação computacional de técnicas numéricas envolvidas na modelagem do ciclo biogeoquímico do carbono e do enxofre desenvolvido por Garrels e Lerman.

b ) Teste do modelo no estado estacionário e no estado não estacionário

c ) Averiguação da utilização dos métodos numéricos de Runge-Kutta e AdamsMoulton.

d ) Estudo da distribuição dos valores dos níveis quantitativos e análise dos parâmetros associados ao modelo isotópico. 


\section{MATERIAL E MÉTODOS}

Esta seção trata de alguns aspectos relevantes sobre a termodinâmica dos processos irreversíveis que fornece uma ferramenta conceitual útil na organização das idéias sobre o equilíbrio e a evolução dos sistemas geoquímicos.

A consecução de um estudo por modelagem comumente envolve a adoção de um conjunto de procedimentos, que freqüentemente conduzem a uma estimativa das qualidades que contribuem direta ou indiretamente com o tema em estudo. Dentre esses procedimentos, podem ser identificadas algumas fases que serão descritas neste capítulo: considerações físico-químicas; formulação cinética e desenvolvimento numérico do modelo e aspectos computacionais na implementação do modelo.

\subsection{Considerações físico-químicas}

Observando um modelo global, constata-se que um número muito grande de elementos químicos se ordenam ciclicamente de forma mais ou menos regular e organizada. Diferentes minerais desempenham no ambiente de superficie um número complexo de processos geoquímicos, que são responsáveis por uma parte do funcionamento do sistema exógeno.

A termodinâmica estabelece princípios universais que prevêem que os sistemas físicos e químicos, só podem evoluir espontaneamente a partir de estados iniciais de maior energia. Durante estas transformações, pelo menos uma parte dessa energia disponível inicial vem a transformar-se e perder-se, sob a forma de entropia (multiplicada por temperatura absoluta), que é uma grandeza relacionada com a grau de desordem e diversificação de qualquer sistema.

O estado de um sistema geoquímico é especificado por valores de certas grandezas mensuráveis experimentalmente, chamadas de variáveis de estado ou propriedades de estado. As variáveis de estado de um sistema geoquímico que são proporcionais a sua massa, são chamadas de variáveis extensivas, como por exemplo o volume e a energia total do sistema., enquanto que, as propriedades independentes da massa são chamadas de variáveis intensivas do sistema geoquímico. A temperatura e a pressão de qualquer sistema são exemplos de variáveis intensivas. 
O surgimento da biosfera teria acrescido, à ordem inorgânica e cristalina, uma organização funcional complexa, menos ordenada porém mais organizada. Assim, o carbono inorgânico cristalino (diamante ou grafite) é transformado em carbono orgânico parcialmente amorfo, como no carvão vegetal em função dos compostos de origem bioquímica que mantém uma certa organização a nível molecular .

Em sua evolução dinâmica, um sistema geoquímico conserva uma série de propriedades dos sistemas lineares que variam continuamente na medida em que se distanciam do equilíbrio termodinâmico. Conforme o aumento deste afastamento, o sistema atravessa múltiplas zonas de estabilidade, transformando seu comportamento qualitativamente. Sendo assim, a condição de distância do equilíbrio impõe ao sistema uma nova atividade, que se organiza espontaneamente a partir dela.

Segundo Richardson e McSween Jr. (1989), os sistemas geoquímicos variam entre os estados de equilíbrio termodinâmico através de uma seqüência de padrões evolutivos. $O$ estudo de cada padrão, ao longo do qual um sistema geoquímico pode evoluir, é geralmente obtido pelo seu tratamento cinético dado por uma modelagem numérica de ciclos geoquímicos, que operam em escala global, no tempo geológico.

A presente investigação será conduzida através de experiências essencialmente numéricas, a partir de formulações cinéticas de estados estacionários e não estacionários ou transientes de ciclos geoquímicos. 


\subsection{Formulação cinética do modelo}

O ciclo geoquímico fornece um conceito útil para a discussão de muitos aspectos geoquímicos. Em particular, permite acompanhar o curso seguido por determinados elementos químicos ao progredir por diferentes reservatorios e estágios relacionados aos processos que interferem no meio ambiente.

A construção do modelo global exige o conhecimento da natureza dos fenômenos cíclicos geoquímicos envolvidos, da escolha de referenciais de balanço de massa global e dos coeficientes cinéticos de transferência de massa.

(a)

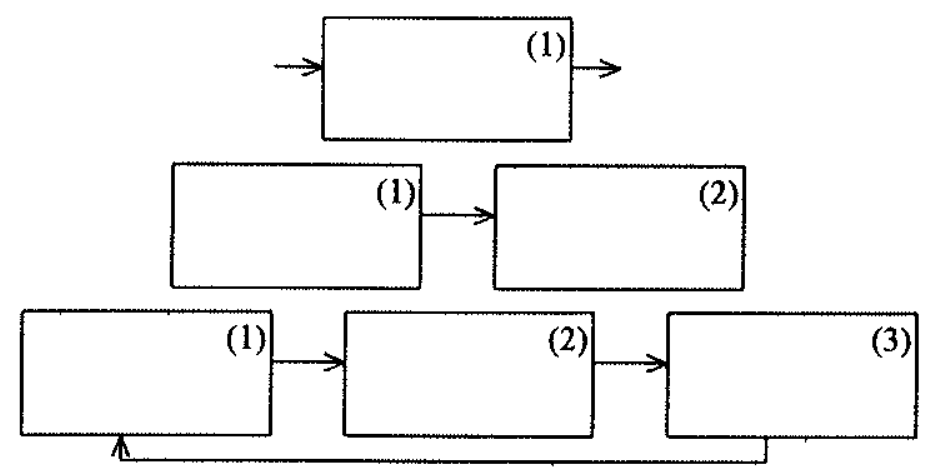

Fig.4 - Diagramas simplificados de reservatórios e transferências.(Holland - 1978).

Conforme Holland (1978), um reservatório é uma representação simplificada da relação de causa e efeito entre a entrada e a saída de um sistema físico, que proporciona uma maneira conveniente e útil para se caracterizar as relações funcionais entre vários subsistemas do ciclo exógeno global. A forma mais simples de um reservatório é apresentada pelo diagrama da Figura (4a) com uma entrada e uma saída, onde o sentido da flecha representa a direção dos fluxos materiais.

Os reservatórios podem ser acumulativos ou não acumulativos em relação aos seus componentes químicos. Pela Figura (4b), se um determinado componente químico i se desloca no sentido do reservatório 1 para o reservatório 2 , a quantidade ${ }_{2} \mathrm{n}_{\mathrm{i}}$ no reservatório 2 é dada pela expressão:

$$
{ }_{2} n_{i}={ }_{2}^{0} n_{i}+\int_{0}^{t} \frac{d_{1,2} n_{i}}{d t} d t
$$


onde ${ }_{2}^{0} n_{i}$ é igual a quantidade do componente i no reservatório 2 quando $t=0$ e, $d_{i, 2} n_{1} / d t$ representa a velocidade de fluxo do componente i do reservatório 1 para o reservatório 2 . Se o reservatório 2 não contém nenhum componente i inicialmente, então:

$$
{ }_{2} n_{i}=\left(\frac{d_{1,2} n_{i}}{d t}\right) \cdot \Delta t
$$

onde $\left(d_{1,2} n_{i} / d t\right)$ é a velocidade média de acumulação do componente $i$ no reservatório 2 durante o intervalo de tempo $\Delta \mathrm{t}$, sendo assim:

$$
\Delta t=\frac{{ }_{2} n_{i}}{\left(\frac{d_{1,2} n_{i}}{d t}\right)}
$$

$\mathrm{O}$ tempo $(\Delta \mathrm{t})$, durante o qual o reservatório 2 pode acumular o componente i é igual a quantidade total do componente i no reservatório 2, dividido pela velocidade média dos fluxos entrada. Essa relação é chamada de tempo característico. Por outro lado, se as velocidades médias dos fluxos de saída do componente i no reservatório 2 forem próximas às velocidades médias dos fluxos de entrada, diremos que o reservatório é não-acumulativo em relação ao componente $\mathrm{i}$.

Sob o ponto de vista geoquímico, o oceano pode ser representado por um reservatório não acumulativo em relação a seus ions mais abundantes. Na figura $(4 \mathrm{c})$, o reservatório 2 é não acumulativo. A variação da quantidade do componente i no reservatório depende das velocidades dos fluxos de entrada e de saída expressos por:

$$
\frac{d_{2} n_{i}}{d t}=\frac{d_{1,2} n_{i}}{d t}-\frac{d_{2,3} n_{i}}{d t}
$$

Se o sistema se encontra em equilíbrio dinâmico, a velocidade dos fluxos de entrada é igual à velocidade dos fluxos de saída, e a quantidade ${ }_{2} \mathrm{n}_{\mathrm{i}}$ permanece constante. Neste caso o tempo característico ${ }_{2} \tau_{\mathrm{i}}$ é definido por:

$$
{ }_{2} \tau_{i}=\frac{{ }_{2} n_{i}}{d_{1,2} n_{i} / d t}=\frac{{ }_{2} n_{i}}{d_{2,3} n_{i} / d t}
$$


que, geoquímicamente, é o tempo requerido para que ${ }_{2} n_{i}$ moles do componente i passem pelo reservatório 2. Portanto ${ }_{2} \tau_{\mathrm{i}}$ é o tempo de residência médio do componente $\mathrm{i}$ no reservatório 2 , quando o reservatório está em estado estacionário em relação ao componente $\mathrm{i}$.

No estado não estacionário, ou estado transiente, os fluxos de entrada em um determinado reservatório não são balanceados pelos fluxos de saída, podendo-se distinguir dois casos: um mais simples, linear, no qual as velocidades dos fluxos de entrada são independentes do estado do reservatório; e um outro, mais complexo, onde os fluxos de entrada são dependentes do estado do reservatório, podendo ser representados por mecanismos de retroalimentação (Figura 4c). No primeiro caso, podemos expressar o comportamento cinético por:

$$
\frac{d_{j} n_{i}}{d t}={ }_{j} f_{i}(t)-{ }_{j} k_{i} g\left({ }_{j} n_{i}\right)
$$

onde $\mathrm{f}_{\mathrm{i}}(\mathrm{t})$ é o fluxo de entrada no reservatório $\mathrm{i}, \mathrm{j}_{\mathrm{j}}$ é a constante cinética de primeira ordem, e $g\left({ }_{j} n_{i}\right)$ representa uma função do estado do reservatório, especificado pelos valores de suas variáveis de estado.

Dois ou mais reservatórios podem apresentar mecanismos característicos de retroalimentação no sistema definidos pela estabilidade ou instabilidade de seus constituintes químicos individuais. Para Kump (1989b), quando os fluxos de massa entre os reservatórios encontram-se em estado não-estacionário ou transiente, esta condição se apresenta como localmente estável, globalmente estável ou instável. Em um estado globalmente estável, o sistema pode ser perturbado, mas retorna sempre ao mesmo estado inicial. $O$ estado localmente estável não é afetado por pequenas perturbações. Quando os estados instáveis são perturbados, o sistema pode atingir um novo estado estacionário com características geoquímicas diferentes.

Segundo Lasaga (1980) e (1981), ciclos geoquímicos lineares apresentam comportamentos cinéticos descritos por sistemas de equações diferenciais lineares de primeira ordem, cuja estabilidade é uma característica que depende somente do sistema, enquanto que ciclos geoquímicos que comportam mecanismos de retroalimentação são descritos por sistemas de equações diferenciais não lineares. 
O tratamento numérico dos estados estacionários do ciclo geoquímico, assim como os estados não estacionários, é resolvido por uma variedade de técnicas computacionais que serão discutidas oportunamente. 


\subsection{Desenvolvimento numérico do modelo isotópico}

Este capítulo trata do desenvolvimento numérico do modelo isotópico para os ciclos sedimentares de carbono e enxofre, proposto por Garrels e Lerman (1984), pelo qual se interpreta o comportamento conjugado de ambos os ciclos.

$\mathrm{O}$ modelo se baseia no estudo do ciclo do carbono conjugado com o ciclo do enxofre, elaborado a partir dos principais mecanismos de oxi-redução envolvidos nos ciclos biogeoquímicos das rochas sedimentares e no registro isotópico do sulfato e do carbonato marinho durante o Fanerozóico, formulados cinéticamente a partir dos estados estacionários e não estacionários dos reservatórios que compõem o ciclo global.

Em geral, os estudos que envolvem a simulação desses ciclos são úteis como um referencial inicial para se estudar algumas mudanças globais significativas, em relação ao ambiente de superficie.

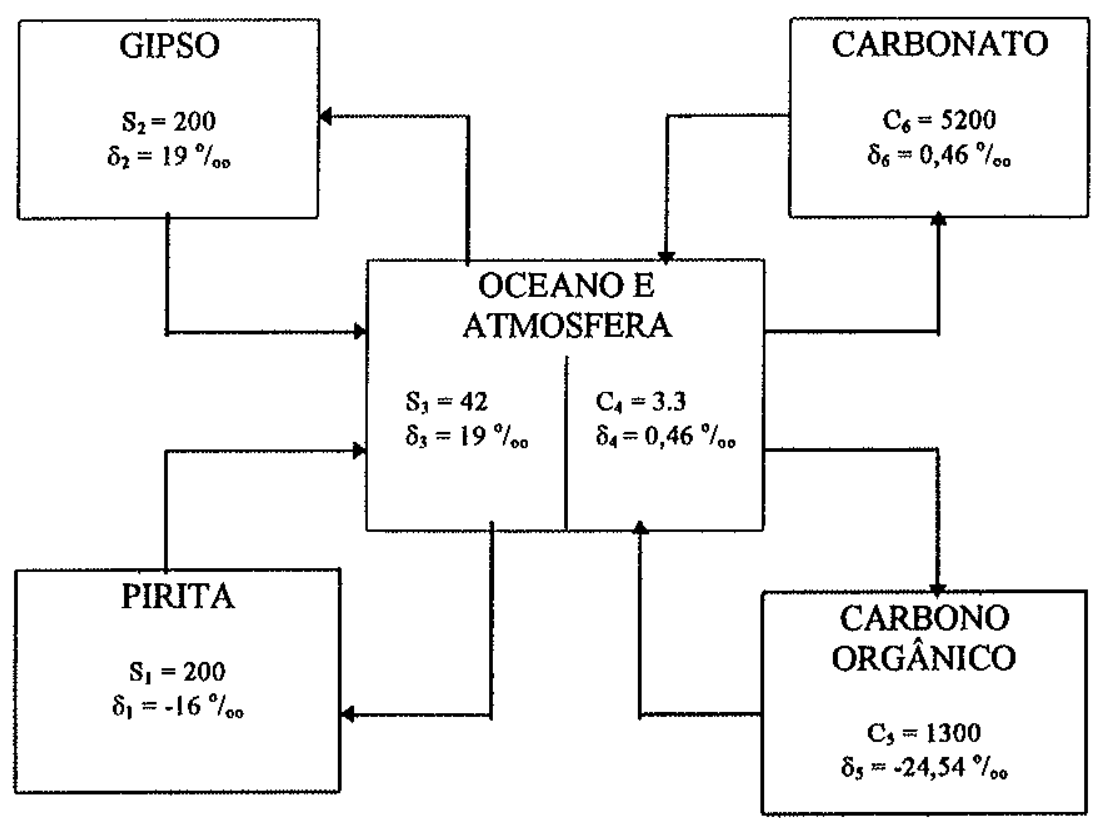

Fig.5 -Teor dos reservatórios (em unidades de $10^{18}$ moles ) e composição isotópica do carbono e do enxofre nos reservatórios de gipso, de pirita, de carbonatos e de carbono orgânico (Garrels e Lerman, 1984). 
Pelo diagrama da Figura (5), as estimativas das massas oxidadas e reduzidas de carbono e enxofre nos reservatórios sedimentares (em unidades de $1,0 \times 10^{18}$ moles) são obtidas através da massa total das rochas sedimentares (em torno de $2,5 \times 10^{24}$ gramas). $\mathrm{O}$ fracionamento isotópico entre ${ }^{13} \mathrm{C} /{ }^{12} \mathrm{C}$ e ${ }^{34} \mathrm{~S} /{ }^{32} \mathrm{~S}$ nos reservatórios que compõem a figura é dado pelos valores de $\delta$ e pelos fluxos $\mathrm{F}_{\mathrm{ij}}$ onde $\mathrm{i}$ e $\mathrm{j}$ se referem aos fluxos no sentido do reservatório i para o reservatório $\mathrm{j}$ (em unidades de $10^{18} \mathrm{moles} / \mathrm{milhão}$ de anos), os índices $1,2,3,4,5$ e 6 são atribuídos aos respectivos reservatórios de pirita, gipso, sulfato oceânico, carbonato oceânico, carbono orgânico e carbonatos, dados pela sua ordem de transferência.

Nesse sistema, a composição química oceânica e atmosférica permanecem constantes, de modo que a soma dos fluxos de entrada de material, no reservatório oceanoatmosfera, devem ser iguais a soma dos fluxos do material de saída. Como, em princípio, o sistema encontra-se em estado estacionário, uma flutuação no ciclo do carbono deve ser correspondida a uma outra flutuação no ciclo do enxofre. Para que o reservatório atmosfera-oceano permaneça constante em relação aos seus teores globais, todos os fluxos de entrada de material devem ser iguais aos fluxos de saída calculados como :

$$
\begin{aligned}
& F_{13}+F_{23}=F_{31}+F_{32} \\
& F_{54}+F_{64}=F_{45}+F_{46}
\end{aligned}
$$

Os fluxos de intemperismo e transporte de materiais de entrada $\left(F_{13}, F_{23}, F_{54}\right.$ e $\left.F_{64}\right)$ obedecem a um comportamento cinético de primeira ordem, diretamente relacionado às massas do reservatório, dado por:

$$
\mathrm{F}_{\mathrm{i}, \mathrm{j}}=\mathrm{k}_{\mathrm{i}, \mathrm{j}} \cdot \mathrm{M}_{\mathrm{i}} \quad \text { (massa/tempo) }
$$

onde $\mathrm{M}_{\mathrm{i}}$ é a massa de cada reservatório, e $\mathrm{k}_{\mathrm{ij}}$ é a respectiva constante cinética de primeira ordem.

Em relação ao ciclo do enxofre na Figura (5), a massa total do sistema, assim como a sua composição isotópica média podem ser expressas por : 


$$
\begin{gathered}
S_{1}+S_{2}+S_{3}=S_{T} \\
\delta_{1} S_{1}+\delta_{2} S_{2}+\delta_{3} S_{3}=\delta S_{T}
\end{gathered}
$$

onde cada $S_{i}$ se refere ao respectivo reservatorio de enxofre, $S_{T}$ se refere ao total dos reservatórios de enxofre e os $\delta$ são as variações dos valores dos fracionamentos isotópicos.

As variações na composição isotópica de enxofre nos oceanos são dadas pelo balanço de massa de seus fluxos de entrada e remoção, conforme a equação:

$$
\delta_{1} \mathrm{~F}_{13}+\delta_{2} \mathrm{~F}_{23}=\left(\delta_{3}-\alpha s\right) \mathrm{F}_{31}+\delta_{3} \mathrm{~F}_{32}
$$

onde $\alpha s(=35 \%$ é uma constante relacionada ao fracionamento isotópico que ocorre durante os processos de redução biológica.

Numericamente, o ciclo do carbono pode ser mais simples de que o ciclo do enxofre. A estequiometria dada pela reação de balanço de massa global que descreve o ciclo sedimentar, indica que a massa de carbono orgânico estocada em um certo período de tempo $\left(\Delta \mathrm{C}_{5}\right)$ está relacionada por um fator de $15 / 8$ da massa de enxofre do reservatório de gipso (reservatório 2).

$$
\Delta \mathrm{C}_{5}=\frac{15}{8} \cdot \frac{\mathrm{dS}}{\mathrm{dt}} \cdot \Delta \mathrm{t}
$$

A conjugação entre os ciclos de carbono e enxofre representada pela equação (33) utiliza os valores de sulfato sedimentar $\left(S_{2}\right)$ para estimar os teores do reservatório de carbono e seus fluxos. Considerando que o ciclo o carbono opera sob um conjunto de condições análogas ao ciclo do enxofre, o balanço total de massa dos reservatórios sedimentares de carbono, assim como o balanço das suas massas isotópicas são dados por:

$$
\begin{gathered}
\mathrm{C}_{4}+\mathrm{C}_{5}+\mathrm{C}_{6}=\mathrm{C}_{\mathrm{T}} \\
\delta_{4} \mathrm{C}_{4}+\delta_{5} \mathrm{C}_{5}+\delta_{6} \mathrm{C}_{6}=\delta \mathrm{C}_{\mathrm{T}}
\end{gathered}
$$

O balanço isotópico das massas oceânicas, também supõe sucessivos estados estacionários a cada um milhão de anos no caso do carbono: 


$$
\delta_{5} \mathrm{~F}_{34}+\delta_{6} \mathrm{~F}_{64}=\left(\delta_{4}-\alpha \mathrm{c}\right) \mathrm{F}_{45}+\delta_{4} \mathrm{~F}_{46}
$$

onde $\alpha c(=25 \%)$ é uma constante que está relacionada ao fracionamento isotópico durante os processos de redução biológica.

A solução do método que fornece a descrição dinâmica do modelo apresentado na Figura (5) é resolvida pelo sistema de equações diferenciais ordinárias lineares de primeira ordem, dado por:

$$
\begin{aligned}
& \frac{d S_{1}}{d t}=F_{31}+F_{13} \\
& \frac{d S_{2}}{d t}=F_{32}+F_{23} \\
& \frac{d C_{5}}{d t}=F_{45}+F_{54} \\
& \frac{d C_{6}}{d t}=F_{46}+F_{64} \\
& \frac{d O_{2}}{d t}=F_{45}+15 / 8 F_{31}-15 / 8 F_{13}-F_{54} \\
& \frac{d\left(\delta_{1} S_{1}\right)}{d t}=\left(\delta_{3}-\alpha c\right) F_{31}-\delta_{1} F_{13} \\
& \frac{d\left(\delta_{2} S_{2}\right)}{d t}=\delta_{3} F_{32}-\delta_{2} F_{32} \\
& \frac{d\left(\delta_{5} C_{5}\right)}{d t}=\left(\delta_{4}-\alpha c\right) F_{45}-\delta_{5} F_{45} \\
& \frac{d\left(\delta_{6} C_{6}\right)}{d t}=\delta_{4} F_{46}-\delta_{6} F_{64}
\end{aligned}
$$

Os valores iniciais utilizados no ajustamento dos dados ao modelo proposto, são apresentados pela Tabela (V), e as constantes cinéticas de primeira ordem para os fluxos de intemperismo $\left(F_{13}, F_{23}, F_{34}, F_{64}\right)$ são dadas por: $k_{13}=0,0025 / 10^{6}$ anos; $k_{23}=0,0050 / 10^{6}$ anos $\mathrm{e} \mathrm{k}_{54}=\mathrm{k}_{64}=0,0019 / 10^{6}$ anos. 
TABELA V

Fracionamento isotópico (o/oo) e teores $\left(\mathrm{em} 10^{18} \mathrm{~mol}\right)$ dos reservatórios de carbono e enxofre . (Tardy, 1987).

Carbono $\left(C_{1} \mathrm{em} 10^{18} \mathrm{~mol}\right)$

$\delta^{13} \mathrm{C}$ dos carbonatos dos oceanos

$\delta^{13} \mathrm{C}$ do carbono orgânico

$\delta^{13} \mathrm{C}$ do carbono nos carbonatos

teor do reservatório $\mathrm{HCO}_{3}^{-}$dos oceanos

teor dos reservatórios de carbonato

teor do reservatório de carbono orgânico

$\delta_{4}=0,5 \%$

$\delta_{5}=\quad-24.5 \%$

$\delta_{6}=0,5 \%$

$\mathrm{C}_{4}=\quad 3.3$

$\mathrm{C}_{5}=\quad 5200$

$\mathrm{C}_{6}=1300$

Enxofre ( $S_{1}$ em $\left.10^{18} \mathrm{~mol}\right)$

$\delta^{34} \mathrm{~S}$ do reservatório de pirita

$\delta^{34} \mathrm{~S}$ do reservatório de sulfato

$\delta^{34} \mathrm{~S}$ dos sulfatos oceânicos

teor do reservatónio de pirita

teor do reservatório de sulfato

teor do reservatório $\mathrm{SO}_{4}$ dos oceanos

$\delta_{1}=-16 \%$

$\delta_{2}=19 \%$

$\delta_{3}=19 \%$

$\mathrm{S}_{1}=200$

$S_{2}=200$

$S_{3}=\quad 421$

As principais etapas na elaboração de um programa que descreve o comportamento dinâmico do ciclo sedimentar do carbono e do enxofre envolvem, inicialmente, o ajuste dos dados da Figura (5) ao sistema de equações diferenciais (37) a (45) e a escolha do método numérico mais adequado.

Neste trabalho dois métodos numéricos (Runge-Kutta e Adams-Moulton) foram adotados para a solução do sistema de equações diferenciais ordinárias, por serem de mais simples programação e satisfazer o objetivo de construir o algoritmo numérico para o modelo de Garrels e Lerman (1984). 


\subsection{Métodos numéricos}

Ao estudar alguns fenòmenos fisicos, é dificil estabelecer diretamente o caráter de dependência entre uma variável independente $\mathrm{x}$ e uma variável dependente $\mathrm{y}$. No entanto, estabebece-se mais facilmente a relą̧ão entre $x, y$ e as derivadas $y^{\prime}(x), y^{\prime \prime}(x), \ldots y^{(n)}(x)$ que constitui uma equação diferencial. Resolver aproximadamente equações diferenciais é um dos grandes problemas da análise numérica. O problema clássico do valor inicial consiste em determinar uma função $y(x)$ que verifica a equação diferencial de primeira ordem $y^{\prime}=f(x, y)$ tomando o valor inicial $y\left(x_{0}\right)=y_{0}$. Existe uma variedade de métodos para a resolução deste problema, alguns dos quais foram generalizados para eqauções de ordem superior à primeira. Neste trabalho trataremos apenas do caso das equações de primeira ordem.

Os fenômenos fisicos, na sua grande maioria, são modelados através de sistemas de Equações Diferenciais Ordinárias, cuja variável independente é o tempo, que envolve uma função desconhecida, e algumas de suas derivadas até a ordem n que podem ser escrita como:

$$
y^{(n)}(x)=f\left(x, y(x), y^{\prime}(x), y^{\prime \prime}(x), \ldots, y^{(n-1)}(x)\right), \quad a \leq x \leq b
$$

A solução da equação (46) é uma função $y=f(x)$ definida em um intervalo $[a, b]$ com n derivadas neste intervalo. Um sistema de equaçðes diferenciais de primeira ordem apresenta a seguinte forma geral:

$$
\begin{aligned}
& y_{1}{ }^{\prime}(x)=f_{1}\left(x, y_{1}, y_{2}, y_{3}, \ldots, y_{n}\right) \\
& y_{2}{ }^{\prime}(x)=f_{2}\left(x, y_{1}, y_{2}, y_{3}, \ldots, y_{n}\right) \\
& y_{n}{ }^{\prime}(x)=f_{n}\left(x, y_{1}, y_{2}, y_{3}, \ldots, y_{n}\right)
\end{aligned} \quad a \leq x \leq b
$$

onde $y_{k}(a)=n_{k}, k=1(1) n$ e $f_{k}, f_{2}, \ldots$ fn são funções de $n+1$ variáveis.

As soluções do sistema são derivadas da solução de uma única equação que pode ser escrita como:

$$
y^{(n)}(x)=f\left(x, y_{1}, y_{2}, y_{3}, \ldots, y_{n}\right) .
$$

Determinar numéricamente uma solução de uma equação diferencial é encontrar os valores $y_{1}, y_{2}, y_{3} \ldots y_{n}$ através de uma aproximação de equação de diferenças. Tal aproximação introduz um erro de truncamento e um erro de arredondamento. Existe uma 
variedade de métodos numéricos para a resolução desse sistema. Este trabalho, tratamos apenas do caso de um sistema de Equações Diferenciais Ordinárias lineares de primeira ordem que calcula uma seqüência de valores $y_{k}$ correspondentes a um conjunto discreto de argumentos $x_{k}$. Se $f(x, y)$ é uma função definida em um certo intervalo, podem ser obtidas as sucessivas derivadas de $\mathrm{y}(\mathrm{x})$ através dos métodos de Runge-Kutta ou dos métodos preditores-corretores como o de Adams-Moulton.

O método de Runge-Kutta procura calcular a direção a seguir em uma extrapolação usando valores médios ponderados da derivada da função, calculados em pontos selecionados de cada subintervalo enquanto que, o método de Adams-Moulton envolve o uso de uma fórmula para prever o valor seguinte de $y_{k}$, seguido pela aplicação de uma fórmula corretora mais precisa. Embora um pouco complexo, estes métodos tem a vantagem de permitir uma estimativa do erro a partir das sucessivas aproximaçð̃es de cada $y_{k}$.

Para alcançar estes objetivos foi utilizada a biblioteca IMSL, que é um conjunto abrangente de subrotinas matemáticas escritas em linguagem Fortran, testadas pela empresa IMSL Inc., e que permite a construção de programas relacionados ao comportamento dinâmico de ciclos geoquímicos. A utilização deste e de outros aplicativos que compõem a organização do ambiente de programação, necessário à modelagem, será discutida posteriormente. 


\subsubsection{Aspectos computacionais na implementação do método}

Esta seção procura abordar, de maneira resumida, os principais aspectos relacionados ao ambiente básico de programação e ao material preliminar necessário à computação numérica.

Genericamente, pode-se definir um modelo numérico de ciclo geoquímico como uma relação matemática entre grandezas particulares, baseado em certos conceitos termodinâmicos e cinéticos que são os elementos centrais do planejamento do experimento matemático e do processamento dos dados observados.

A computação científica tem por objetivo estudar processos numéricos (algoritmos) para a solução de problemas, visando a máxima economia e confiabilidade em termos dos fatores envolvidos. Como estes algoritmos são implementados em computadores, os fatores envolvidos podem ser: o tempo de execução, a memória utilizada e as fontes de erro.

Os algoritmos variam de acordo com os tipos de equações diferenciais envolvidas. Como normalmente temos vários métodos para a resolução de um problema, torna-se conveniente a escolha daquele que é mais eficiente. Essa eficiência pode ser medida considerando-se principalmente a análise dos erros e o esforço dispendido na obtenção dos mesmos.

Com respeito ao esforço para obtenção dos resultados, para cálculos computacionais devemos minimizar tanto quanto possível o número de operações pois, quanto maior o número de operações envolvidas num processo de simulação, tanto maior será o tempo de máquina para a sua execução, e mais sujeitos estarão os resultados aos erros.

Desta forma podemos dizer que o esforço computacional de um método numérico é o número total de operações necessárias para a obtenção dos resultados. $\mathrm{O}$ cálculo do esforço computacional exige uma análise minuciosa do algoritmo, do processo de programação e da análise dos erros. Existem vários tipos de erros e várias são as suas causas. Os três tipos de erros mais comuns são: os inerentes, os de discretização e os de arredondamento.

Os erros inerentes aparecem na criação ou simplificação de um modelo matemático de determinado sistema; os erros de discretização, aproximação ou truncamento são os erros cometidos quando se substitui qualquer processo infinito por um processo finito ou 
discreto e, os erros de arredondamento surgem quando trabalhamos com as limitações das máquinas digitais para representar os números reais.

Em qualquer processo numérico que envolve um razoável esforço computacional, os erros de arredondamento cometidos após cada operação se acumulam, podendo também afetar o resultado final.

Os métodos de Runge-Kutta e Adams-Moulton são baseados na repetição de uma seqüência de operações que utilizam o último valor computado $\left(\mathrm{y}_{\mathrm{k}}\right)$ para calcular o valor seguinte $\left(y_{k+1}\right)$ de uma determinada função. Se o resultado de cada operação é afetado por erros, eles geralmente se somam, e o n-ésimo valor de y é afetado por um erro acumulado.

\subsubsection{Ambiente de programação}

Os três principais aplicativos necessários para a implementação do método, baseados no sistema operacional MS-DOS ou PC-DOS incluem, um editor de texto; um compilador Microsoft Fortran, versão de no mínimo 4.01 e a Biblioteca IMSL versão 1.1, um conjunto de sub-rotinas para aplicação matemática, escritas em Fortran. Este material encontra-se disponível na programoteca do Centro de Computação Eletrônica da Universidade de São Paulo.

Inicialmente, é criado um algoritmo numérico do modelo em estudo, que define e inicializa as variáveis geoquímicas envolvidas, com passos bem definidos, e caracterizados pela inexistência de erro lógico e operacional. Posteriormente, este algoritmo é escrito em linguagem de alto nível criando um programa fonte em Fortran usando o editor de texto. Esse programa é então compilado e carregado com partes relevantes da biblioteca IMSL, cujas instruções são traduzidas para a linguagem de máquina, isto é, valores que representam instruções para o microprocessador e, finalmente, executado para concluir a computação desejada.

A organização do ambiente de programação é ilustrada no esquema abaixo dado pela Figura (6). 


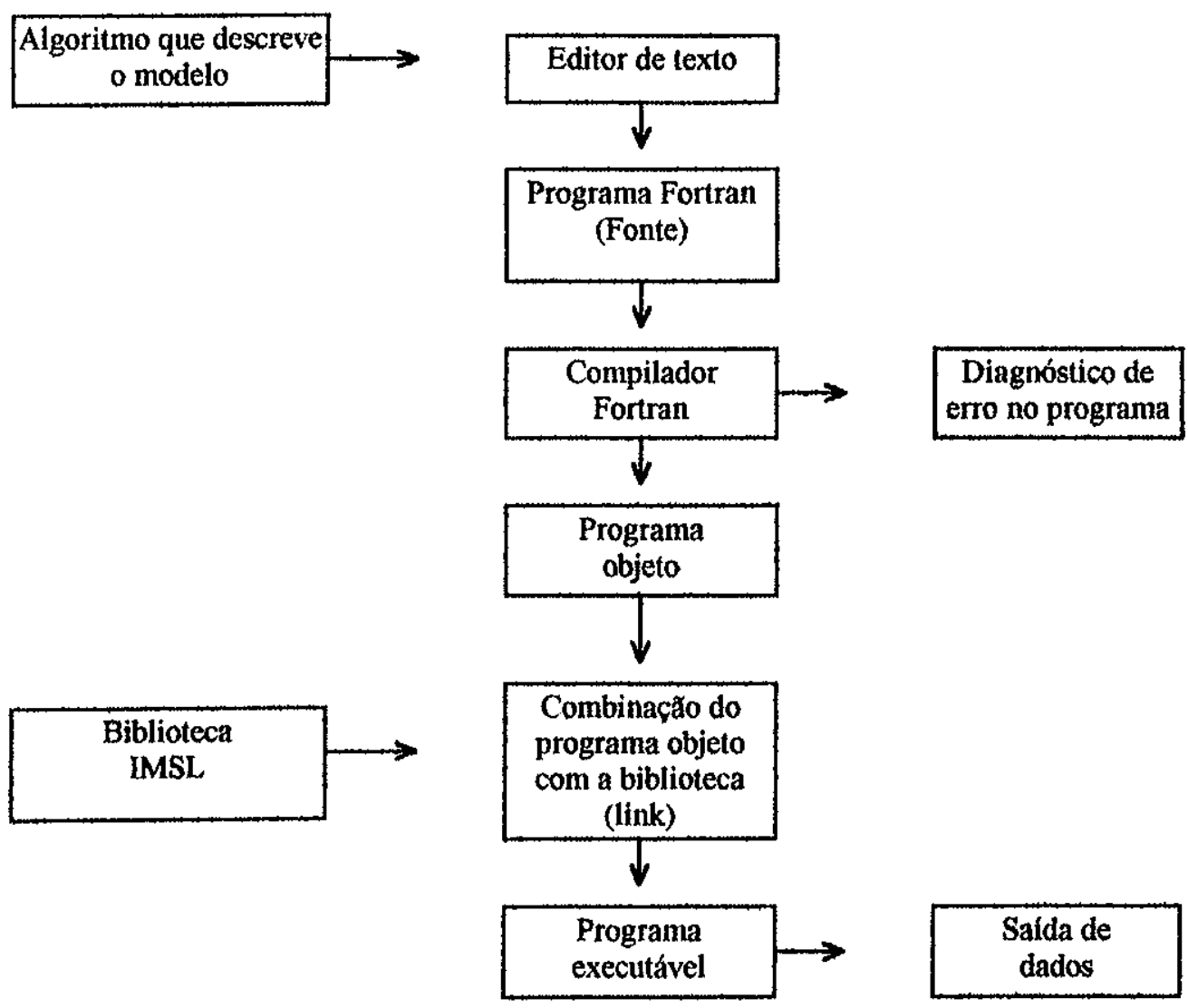

Fig. 6- Configuração simplificada do ambiente de programação (Rice - 1993) 


\section{RESULTADOS E DISCUSSÃO}

Para a execução dos cálculos do modelo isotópico foram desenvolvidos três programas distintos, em linguagem Fortran, baseados no ambiente computacional descrito pela Figura (6). O primeiro programa teve como finalidade confrontar os resultados desenvolvidos por Garrels e Lerman (1984) seguindo os procedimentos expostos neste trabalho, considerando inicialmente que o sistema sedimentar global encontra-se em estado estacionário, em relação aos seus reservatórios e utilizando o método de Adams-Moulton para o sistema de Equações Diferenciais Ordinárias (37) a (45). Este programa foi aqui denominado Galer l, que é uma simplificação das iniciais de Garrels e Lerman. O segundo programa, denominado Galer2, foi elaborado supondo que o mesmo sistema sedimentar encontra-se em estado não estacionário em relação aos seus reservatórios e introduzindo outros dados iniciais, (Berner 1987), visando detectar a reprodutibilidade qualitativa dos diversos parâmetros envolvidos no modelo, utilizando também o método numérico de Adams-Moulton. O terceiro programa, Galer3, teve como finalidade verificar a sensibilidade quanto ao método numérico aplicado, considerando que o sistema encontra-se em estado não estacionário, nas mesmas condições iniciais do programa anterior, utilizando o método de Runge-Kutta.

Alguns ajustes iniciais são requeridos para se determinar a sensibilidade dos programas desenvolvidos. A análise da sensibilidade tem como princípio introduzir algumas alterações no algoritmo inicial e observar sua resposta, com o objetivo de se detectar possíveis instabilidades em alguma parte da computação, que possam afetar a solução final. Para cada programa foi introduzido um reservatório explícito de oxigênio atmosférico, com o objetivo de se testar algumas hipóteses iniciais, bem como os fluxos de soterramento de carbono e enxofre $\left(F_{45}\right.$ e $\left.F_{31}\right)$ que foram tratados no algoritmo também como funções explícitas. Além do mais, os programas foram calculados para o período de 10 milhões de anos atrás, em função dos recursos de programação utilizados. Os resultados se encontram nas Tabelas VI, VII e VIII. 


\section{TABELA VI}

Experimento 1, programa Galer 1, método de Adamns-Moulton para o estado estacionário onde : pirita $\left(S_{1}\right)$; gipso $\left(S_{2}\right)$; carbono orgânico $\left(C_{5}\right)$; carbonato $\left(C_{6}\right)$; oxigênio atmosférico $\left(O_{2}\right)$ e os isótopos de sulfeto $\left(\delta_{1}\right)$; sulfato $\left(\delta_{2}\right)$; carbono orgânico $\left(\delta_{5}\right)$; calcita $\left(\delta_{6}\right)$ e sulfeto e carbono orgânico oceânico respectivamente $\left(\delta_{3}\right.$ e $\left.\delta_{4}\right)$.

\begin{tabular}{|c|c|c|c|c|c|c|c|c|c|c|c|c|c|}
\hline tempo & $\mathrm{S}_{1}$ & $\mathrm{~S}_{2}$ & $\mathrm{~F}_{31}$ & $\mathrm{~F}_{45}$ & $\mathrm{C}_{5}$ & $\mathrm{C}_{6}$ & $\mathrm{O}_{2}$ & $\delta_{1}$ & $\delta_{2}$ & $\delta_{3}$ & $\delta_{4}$ & $\delta_{5}$ & $\delta_{6}$ \\
\hline 0 & 200.00 & 200.00 & 0,50 & 2.47 & 1300.0 & 5200.0 & 38.00 & -16.00 & 19.00 & 19.00 & 0.46 & -24.54 & 0.46 \\
-1 & 200.00 & 200.00 & 0,50 & 2.47 & 1300.0 & 5200.0 & 38.00 & -16.00 & 19.00 & 19.00 & 0.46 & -24.54 & 0.46 \\
-2 & 200.00 & 200.00 & 0,50 & 2.47 & 1300.0 & 5200.0 & 38.00 & -16.00 & 19.00 & 19.00 & 0.46 & -24.54 & 0.46 \\
-3 & 200.00 & 200.00 & 0,50 & 2.47 & 1300.0 & 5200.0 & 38.00 & -16.00 & 19.00 & 19.00 & 0.46 & -24.54 & 0.46 \\
-4 & 200.00 & 200.00 & 0,50 & 2.47 & 1300.0 & 5200.0 & 38.00 & -16.00 & 19.00 & 19.00 & 0.46 & -24.54 & 0.46 \\
-5 & 200.00 & 200.00 & 0,50 & 2.47 & 1300.0 & 5200.0 & 38.00 & -16.00 & 19.00 & 19.00 & 0.46 & -24.54 & 0.46 \\
-6 & 200.00 & 200.00 & 0,50 & 2.47 & 1300.0 & 5200.0 & 38.00 & -16.00 & 19.00 & 19.00 & 0.46 & -24.54 & 0.46 \\
-7 & 200.00 & 200.00 & 0,50 & 2.47 & 1300.0 & 5200.0 & 38.00 & -16.00 & 19.00 & 19.00 & 0.46 & -24.54 & 0.46 \\
-8 & 200.00 & 200.00 & 0,50 & 2.47 & 1300.0 & 5200.0 & 38.00 & -16.00 & 19.00 & 19.00 & 0.46 & -24.54 & 0.46 \\
-9 & 200.00 & 200.00 & 0,50 & 2.47 & 1300.0 & 5200.0 & 38.00 & -16.00 & 19.00 & 19.00 & 0.46 & -24.54 & 0.46 \\
-10 & 200.00 & 200.00 & 0,50 & 2.47 & 1300.0 & 5200.0 & 38.00 & -16.00 & 19.00 & 19.00 & 0.46 & -24.54 & 0.46 \\
\hline
\end{tabular}




\section{TABELA VII}

Experimento 2, programa Galer 2, método de Adams-Moulton para o não estado estacionário onde : pirita $\left(S_{1}\right)$; gipso $\left(S_{2}\right)$; carbono orgânico $\left(C_{5}\right)$; carbonato $\left(C_{6}\right)$; oxigênio atmosférico $\left(\mathrm{O}_{2}\right)$ e os isótopos de sulfeto $\left(\delta_{1}\right)$; sulfato $\left(\delta_{2}\right)$; carbono orgânico $\left(\delta_{5}\right)$; calcita $\left(\delta_{6}\right)$ e sulfeto e carbono orgânico oceânico respectivamente $\left(\delta_{3}\right.$ e $\left.\delta_{4}\right)$.

\begin{tabular}{|c|c|c|c|c|c|c|c|c|c|c|c|c|c|}
\hline tempo & $\mathrm{S}_{1}$ & $\mathrm{~S}_{2}$ & $\mathrm{~F}_{31}$ & $\mathrm{~F}_{45}$ & $\mathrm{C}_{5}$ & $\mathrm{C}_{6}$ & $\mathrm{O}_{2}$ & $\delta_{1}$ & $\delta_{2}$ & $\delta_{3}$ & $\delta_{4}$ & $\delta_{5}$ & $\delta_{6}$ \\
\hline 0 & 250.03 & 249.97 & 0.93 & 4.50 & 1249.95 & 5000.05 & 38.00 & -15.01 & 20.00 & 18.80 & 1.00 & -23.50 & 1.5 \\
-1 & 249.76 & 250.24 & 0.93 & 4.50 & 1250.45 & 4999.55 & 38.00 & -14.95 & 20.02 & 19.11 & 1.00 & -23.51 & 1.5 \\
-2 & 249.49 & 250.51 & 0.93 & 4.50 & 1250.95 & 4999.05 & 38.00 & -14.89 & 20.04 & 19.42 & 1.01 & -23.51 & 1.5 \\
-3 & 249.23 & 250.77 & 0.93 & 4.50 & 1251.45 & 4998.55 & 38.00 & -14.83 & 20.06 & 19.72 & 1.01 & -23.52 & 1.5 \\
-4 & 248.96 & 251.04 & 0.93 & 4.50 & 1251.95 & 4998.05 & 38.00 & -14.77 & 20.08 & 20.03 & 1.02 & -23.53 & 1.5 \\
-5 & 248.69 & 251.31 & 0.93 & 4.50 & 1252.45 & 4997.55 & 38.00 & -14.71 & 20.10 & 20.34 & 1.02 & -23.54 & 1.5 \\
-6 & 248.43 & 251.57 & 0.93 & 4.50 & 1252.95 & 4997.05 & 38.00 & -14.65 & 20.12 & 20.65 & 1.03 & -23.54 & 1.5 \\
-7 & 248.16 & 251.84 & 0.93 & 4.50 & 1243.45 & 4996.55 & 38.00 & -14.59 & 20.14 & 20.96 & 1.03 & -23.55 & 1.5 \\
-8 & 247.89 & 252.11 & 0.93 & 4.50 & 1253.95 & 4996.05 & 38.00 & -14.53 & 20.16 & 21.27 & 1.04 & -23.56 & 1.5 \\
-9 & 247.63 & 252.37 & 0.93 & 4.50 & 1254.45 & 4995.55 & 38.00 & -14.46 & 20.17 & 21.58 & 1.04 & -23.57 & 1.5 \\
-10 & 247.36 & 252.64 & 0.93 & 4.50 & 1254.95 & 4995.05 & 38.00 & -14.40 & 20.19 & 21.88 & 1.04 & -23.58 & 1.5 \\
\hline
\end{tabular}




\section{TABELA VIII}

Experimento 3, programa Galer 3, método de Runge-Kutta para o não estado estacionário onde : pirita $\left(\mathrm{S}_{1}\right)$; gipso $\left(\mathrm{S}_{2}\right)$; carbono orgânico $\left(C_{5}\right)$; carbonato $\left(C_{6}\right)$; oxigênio atmosférico $\left(\mathrm{O}_{2}\right)$ e os isótopos de sulfeto $\left(\delta_{1}\right)$; sulfato $\left(\delta_{2}\right)$; carbono orgânico $\left(\delta_{5}\right)$; calcita $\left(\delta_{6}\right)$ e sulfeto e carbono orgânico oceânico respectivamente $\left(\delta_{3}\right.$ e $\left.\delta_{4}\right)$.

\begin{tabular}{|c|c|c|c|c|c|c|c|c|c|c|c|c|c|}
\hline tempo & $\mathrm{S}_{1}$ & $\mathrm{~S}_{2}$ & $\mathrm{~F}_{31}$ & $\mathrm{~F}_{45}$ & $\mathrm{C}_{5}$ & $\mathrm{C}_{6}$ & $\mathrm{O}_{2}$ & $\delta_{1}$ & $\delta_{2}$ & $\delta_{3}$ & $\delta_{4}$ & $\delta_{5}$ & $\delta_{6}$ \\
\hline 0 & 250.00 & 250.00 & 0.93 & 4.50 & 1250.00 & 5000.00 & 38.00 & -15.00 & 20.00 & 18.83 & 1.00 & -23.50 & 1.5 \\
-1 & 249.73 & 250.27 & 0.93 & 4.50 & 1250.50 & 4999.50 & 38.00 & -14.94 & 20.02 & 19.13 & 1.00 & -23.51 & 1.5 \\
-2 & 249.47 & 250.53 & 0.93 & 4.51 & 1251.00 & 4999.00 & 38.00 & -14.88 & 20.04 & 19.42 & 1.00 & -23.52 & 1.5 \\
-3 & 249.19 & 250.81 & 0.96 & 4.52 & 1251.49 & 4998.51 & 37.97 & -14.82 & 20.05 & 19.70 & 1.01 & -23.52 & 1.5 \\
-4 & 248.81 & 251.19 & 1.19 & 4.53 & 1251.98 & 4998.02 & 37.75 & -14.76 & 20.08 & 20.06 & 1.01 & -23.53 & 1.5 \\
-5 & 247.76 & 252.24 & 2.69 & 4.55 & 1252.45 & 4997.55 & 36.25 & -14.66 & 20.16 & 21.02 & 1.03 & -23.54 & 1.5 \\
\hline
\end{tabular}


O primeiro experimento (Tabela VI) mostrou-se satisfatório considerando que o sistema se encontra no estado estacionário em relação aos reservatórios do ciclo sedimentar. Apesar da invariabilidade temporal apresentada, esse experimento é útil para se detectar os aspectos relacionados à estruturação do algoritmo numérico.

No segundo experimento (Tabela VII), foi detectada uma correlação qualitativamente significativa entre alguns reservatórios sedimentares não estacionários, dada pela concordância entre as flutuações nos teores do reservatório de sulfato e o valor calculado para os teores de carbono orgânico, conforme a reação (8) de Garrels e Perry, onde a redução de carbonato a carbono orgânico está relacionada com a oxidação de pirita a gipso. Um aumento nos teores dos reservatórios de sulfato $\left(S_{2}\right)$ e carbono orgânico $\left(C_{5}\right)$ é acompanhado pela diminuição dos teores de pirita $\left(\mathrm{S}_{\ell}\right)$ e carbonato $\left(\mathrm{C}_{6}\right)$ sedimentares. $\mathrm{O}$ enriquecimento isotópico oceânico é observado tanto no sulfato $\left(\delta_{3}\right)$ quanto no carbonato $\left(\delta_{4}\right)$. No terceiro experimento (Tabela VIII), a aplicação do método de Runge-Kutta se apresentou razoavelmente estável para um período de cinco milhões de anos

Os métodos de Runge-Kutta possuem a vantagem de serem auto-inicializados, além de serem estáveis e fornecerem boa precisão. Eles não fornecem, contudo, uma estimativa da precisão a ser atingida de modo que não é possivel saber se o passo de integração que está sendo usado é adequado. A segunda maior desvantagem do método de Runge-Kutta consiste na necessidade de serem feitos quatro cálculos de derivadas por intervalo de integração requerendo um maior tempo de programação em relação ao método de AdamsMoulton. Os métodos preditores-corretores, fornecem uma estimativa automática do erro em cada intervalo, permitindo assim, selecionar o passo de integração dentro da precisão requerida, sendo mais rápidos, uma vez que desenvolvem dois cálculos de derivadas por intervalo. Por outro lado, as sub-rotinas relacionadas a esse método são complexas necessitando técnicas especiais para serem inicializadas.

Como previsto pelo modelo de Garrels e Lerman(1984), todo aumento do reservatório de sulfato se traduz por um aumento do fluxo $F_{13}$ proveniente do reservatório (1) de pirita cuja composição isotópica se apresenta mais empobrecida em ${ }^{34} \mathrm{~S}$ em relação ao sulfato. Toda redução no teor do reservatório de pirita e aumento no teor do reservatório de sulfato apresenta um enriquecimento isotópico nos sedimentos marinhos. Observa-se também, pelos resultados das Tabelas VII e VIII, que a formação dos evaporitos é acompanhada pela deposição de carbono orgânico. 
Assim, supondo que as massas totais de carbono e enxofre nos oceanos e nos quatro reservatórios sedimentares e a composição dos oceanos e da atmosfera permanecem constantes durante 10 milhões de anos, as flutuações nos teores dos reservatórios de sulfato e de carbono de um lado e de carbonato e pirita de outro se apresentam no sentido inverso.

No modelo isotópico, a velocidade de produção de oxigênio é igual à velocidade de carbono orgânico soterrado mais $15 / 8$ da velocidade de pirita soterrada e, a velocidade de oxigênio consumido é igual à velocidade de oxidação de carbono orgânico mais $15 / 8 \mathrm{da}$ velocidade de oxidação de pirita:

$$
\frac{\mathrm{dO}_{2}}{\mathrm{dt}}=\left(\mathrm{F}_{45}+\frac{15}{8} \mathrm{~F}_{31}\right)-\left(\mathrm{F}_{54}+\frac{15}{8} \mathrm{~F}_{13}\right)
$$

onde:

$\mathrm{O}_{2}=$ massa do oxigênio atmosférico.

$\mathrm{t}=$ tempo

Substituindo os valores dos fluxos $F_{45}, F_{31}, F_{54}$ e $F_{13}$ na modelagem obtém-se os valores para os diferentes teores para o oxigênio atmosférico em função dos fluxos de massa dos reservatórios sedimentares. Infelizmente, os resultados da Tabela VIII se apresentaram insatisfatórios, com valores excessivamente baixos em relação ao atual teor atmosférico, em curto período de tempo, o que teria sido fatal para algumas formas de vida superior.

Uma alternativa para se resolver este problema, é a introdução de mecanismos de retroalimentação negativo ao sistema de equações (37) a (45) que pode em princípio ser aplicado aos processos de soterramento, intemperismo ou ambos. Por exemplo, um súbito aumento na velocidade de soterramento de carbono orgânico produz um aumento no teor de oxigênio atmosférico e dos processos de intemperismo e oxidação da matéria orgânica, acelerando os processos de oxidação da pirita e do carbono orgânico, consumindo oxigênio atmosférico e restaurando o equilíbrio.

O problema básico na utilização de mecanismos de retroalimentação negativa consiste na conseqüente flutuação de $\mathrm{O}_{2}$ em um curto espaço de tempo, o que seria inviável para a Biosfera. Embora os resultados se apresentem geologicamente razoáveis, o tipo de modelagem numérica desenvolvida neste trabalho não permitiu a possibilidade de simulação para um período maior de tempo. 
A construção de outros modelos sedimentares globais com mecanismos de retroalimentação entre os processos geoquímicos como o "modelo de reciclagem rápida" (Berner 1987), reduz as flutuações dos teores de oxigênio atmosférico por meio de trajetórias mais rápidas ou modelos levando em conta os problemas da estabilidade e da flutuação do sistema (Lasaga 1989).

Essa modelagem apesar de considerar o ciclo exógeno como um sistema fechado, produz resultados qualitativamente válidos para uma aproximação conceitual ao atual regime de sedimentação na superfície do planeta. Verifica-se que o significado das características evolutivas do sistema, pode ser interpretado como conseqüência dos processos de não equilíbrio envolvidos no "metabolismo global" (Gregor et al.1989).

Os apêndices encontrados no final deste trabalho apresentam as listagens de cada experimento numérico.

No apêndice $\mathrm{A}$, os dados iniciais para o estado estacionário são: sulfato = sulfeto $=$ $200 \times 10^{18}$ moles; para o fracionamento isotópico do sulfato: oceano $=19 \%$, gipso $=19 \%$, sulfeto $=-16 \%$; como constantes de intemperismo $\mathrm{k}_{12}=0,0025 / 10^{6}$ anos, $\mathrm{k}_{23}=0,0050 / 10^{6}$ anos.

No apêndice B, os dados iniciais para o estado estacionário são : sulfato = sulfeto = $250 \times 10^{18}$ moles; para o fracionamento isotópico do sulfato: oceano $=20 \%$, gipso $=18,80$ $\%$, sulfeto $=-15 \%$; como constantes de intemperismo $\mathrm{k}_{12}=0,0025 / 10^{6}$ anos, $\mathrm{k}_{23}=$ $0,0050 / 10^{6}$ anos.

No apêndice $\mathrm{C}$, os dados iniciais para o estado estacionário são : sulfato = sulfeto $=$ $250 \times 10^{18}$ moles; para o fracionamento isotópico do sulfato: oceano $=20 \%$, gipso $=18,80$ $\%$, sulfeto $=-15 \%$; como constantes de intemperismo $\mathrm{k}_{12}=0,0025 / 10^{6}$ anos, $\mathrm{k}_{23}=$ $0,0050 / 10^{6}$ anos, utilizando-se o método de Runge-Kutta.

Devido as características computacionais deste trabalho, o programas Galer1, Galer2 e Galer3 encontram-se disponíveis em disquetes, para uma melhor apreciação dos resultados. 


\section{CONSIDERAÇÕES FINAIS}

Uma perturbação na atmosfera pode ser discutida, referindo-nos em épocas recentes, à hipotética adição de gás carbônico $\left(\mathrm{CO}_{2}\right)$ pela queima dos combustíveis fósseis. Uma eventual ocorrência desse excesso fornece boa ilustração para aplicação de alguns dos princípios desenvolvidos neste trabalho.

Supondo que o reservatório global de combustível fóssil seja subitamente convertido em gás carbônico atmosférico, o efeito imediato seria o aumento da pressão parcial de $\mathrm{CO}_{2}$ aumentando a concentração de ácido carbônico e bicarbonato na água do mar e diminuindo o pH oceânico e a velocidade de precipitação de carbonatos. $O$ aumento da pressão parcial de $\mathrm{CO}_{2}$ leva também a um aumento das velocidades dos processo de intemperismo dos carbonatos da crosta, produzindo cátions e adicionando mais carbono que se acumulam no oceano aumentando o seu $\mathrm{pH}$.

$\mathrm{O}$ aumento da concentração de íons carbonatos marinhos leva a um aumento da velocidade de precipitação e diminuição da pressão parcial de $\mathrm{CO}_{2}$ atingindo um novo estado de equilíbrio entre a produção de cálcio e precipitação de carbonato. Esse novo equilíbrio representa um estado intermediário pois o conteúdo de cálcio, como também a concentração de carbonato e a pressão parcial ainda se mantém elevadas durante um certo tempo, em relação ao regime de superficie. $O$ intemperismo dos silicatos fornece o mecanismo necessário para restaurar o equilibrio do sistema nas mesmas condições iniciais (ou condições pré-perturbação).

A longo prazo, o balanço de massa global é feito pelos processos metamórficos que produzem silicatos de cálcio liberando gás carbônico para a atmosfera, através de erupções vulcânicas . $O$ intemperismo do silicato de cálcio, seguido de precipitação do carbonato, remove o carbono do sistema atmosfera-oceano, diminuindo a pressão parcial de $\mathrm{CO}_{2} \mathrm{e}$ aumentando o pH, a concentração dos carbonatos nos oceanos e a velocidade de precipitação em relação à velocidade de intemperismo do carbono.

Portanto, são três os cenários geoquímicos que se distinguem como resposta à adição súbita de $\mathrm{CO}_{2}$ na atmosfera: no primeiro a concentração de ácido carbônico na atmosfera se aproxima do equilíbrio com a pressão parcial de $\mathrm{CO}_{2}$; no segundo, em decorrência do aumento da pressão parcial de $\mathrm{CO}_{2}$, a velocidade do intemperismo da crosta excede a velocidade de precipitação, ocasionando um aumento do conteúdo de cátions no 
oceano; e, no terceiro cenário, o intemperismo do silicato, seguido por precipitação de carbonato restabelece o sistema na condição de equilíbrio inicial.

Neste trabalho apresentou-se o estudo dinâmico de modelos de ciclos geoquímicos globais, como meio de investigação de alguns aspectos ambientais. Entretanto seu emprego sofre restrições impostas por suas hipóteses básicas, limitando-se a tratar de modelos que obedecem comportamento linear. Como aplicação do método, teceram-se considerações sobre a análise da sensibilidade do programa desenvolvido, geralmente assumidas nos trabalhos referentes a modelagem numérica. Apresentou-se o formalismo da implementação do método e o uso da biblioteca IMSL, que por suas características se tornou indispensável a este estudo.

Quanto às limitações do método desenvolvido, a principal restrição se faz quanto às descrições lineares. $O$ emprego de sistemas de equações não lineares pode levar a expressões complexas, sendo mais conveniente para determinar o comportamento irreversível dos ciclos sedimentares.

Quanto aos novos métodos para o estudo desses sistemas, pode-se esperar que os conceitos físico-químicos referentes aos sistemas distantes do equilibrio, venham produzir resultados enriquecedores.

Duas perspectivas se complementam em uma visão evolutiva perante o crescimento da complexidade ambiental. $O$ "presente como a chave do passado" serve para reconstruir alguns cenários freqüentemente mais simples, a partir dos quais puderam proliferar tanto a biosfera, no passado mais remoto, como, atualmente, a esfera humana dos processos tecnológicos, a antroposfera, no sentido geoquímico.

Outra perspectiva surge a partir da leitura do passado perante o leque das alternativas de "possíveis futuros" que cada cenário permite. Desta segunda perspectiva, surge tanto o controle dos modelos adequados à realidade observável, como a visão das alternativas para tomadas de decisão que envolvem o futuro perante as ações humanas. 


\section{REFERÊNCIAS BIBLIOGRÁFICAS}

Berner, R.A., 1982. Soterrado of organic carbon and pyrite sulfur in the modern ocean; its geochemicals and environment sigfnificance. American Journal of Science, 282: 451473.

Berner, R.A., Lasaga, A.C. and Garrels, R.M., 1983. The carbonate-silicate geochemical cycle and its effect on atmospheric carbon dioxide over the past 100 million years. American Journal of Science, 283: 641-683.

Berner, R.A. and Raiswell, R., 1983. Burial of organic carbon and pyrite sulfur in sediments over Phanerozoic time: a new theory. Geochimica et Cosmochimica Acta, 47: 855-862.

Berner, R.A., 1987. Models for carbon and sulfur cycles and atmospheric oxygen: Application to Paleozoic history. American Journal of Science, 287: 177-196.

Berner, E.K. and Berner R.A., 1987. The Global Water Cycle: Geochemistry and Environment. Englewood Cliffs, Prentice-Hall, 397 pp.

Berner, R.A. and Canfield, D.E., 1989. A New Model for Atmospheric Oxygen over Phanerozoic Time. American Journal of Science, 289: 333-361.

Berner, R.A., 1989. Biogeochemical cycles of carbon and sulfur and their effect on a atmospheric oxygen over Fanerozoic time. Palaeogeography, Palaeoclimatology, Palaeoecology. 75: 97-122.

Berner, R.A. 1990. Atmospheric Carbon Dioxide Levels over Phanerozoic Time. Science, 249: 1382-1386.

Berner, R.A., 1991. A Model for Atmospheric $\mathrm{CO}_{2}$ over Phanerozoic Time. American Journal of Science, 291: 339-376. 
Budyko, M.I., Ronov A.B., Yanshin A.L,1987. History of Earth's Atmosphere. Ed. Springer-Verlag-139 pp.

Déleage, J.P. 1993. Historia da Ecologia e da Natureza. Publicações Dom Quixote-276 pp.

Fyfe, W.S. 1981. The Erenvironmental Crisis: Quantifying Geosfere Interactions. Science, $213: 105-110$.

Garrels, R.M. and Mackenzie, F.T., 1971. Evolution of Sedimentary Rocks. New York, Norton, 397 pp.

Garrels, R.M. and Perry, E.A., 1974. Cycling of carbon, sulfur, and oxygen through geologic time. In: Goldberg, E.D. (Editor), The Sea. New York, Wiley N.Y., p. 303316.

Garrels, R.M.; Lerman, A.; Mackenzie, F.T.; 1976. Controls of Atmospheric $\mathrm{O}_{2}$ and $\mathrm{CO}_{2}$. Past, Present and Future. American Scientist, 64: 306-315.

Garrels, R.M. and Lerman, A., 1984. Coupling of the sedimentary sulfur and carbon cycles an improved model. American Journal of Science, 284: 989-1007.

Gear C.W., 1971. Numerical initial value problems in ordinary diferential equations, Prentice-Hall, Englewood Cliffs, N.J. - 250 pp.

Gregor, C.B.; Garrels, R.M.; Mackenzie, F.T.; Maynard, J.B. (1988). Chemical Cycles in the Evolution of the Earth. A Wiley-Interscience Publication. New York. 276pp.

Holland, H.D., 1978. The Chemistry of the Atmospheric and Oceans. New York, Wiley, $351 \mathrm{pp}$.

Holland, H.D., 1984. The Chemical Evolution of the Atmosphere and Oceans. New Jersey, Princeton Univ. Press, $582 \mathrm{pp}$. 
Kump, L.R. and Garrels, R.M., 1986. Modeling atmospheric $\mathrm{O}_{2}$ in the global sedimentary redox cycle. American Journal of Science, 286: 337-360.

Kump, L.R., 1989. Alternative Modeling Approaches to the Geochemical Cycles of Carbon, Sulfur and Strontium Isotopes. American Journal of Science, 289: 390-410.

Kump, L.R. ,1989. Chemical stability of atmosphere and oceans. Palaeogeography, Palaeoclimatology, Palaeoecology, 75: 123-136.

Lasaga, A.C., 1980. The kinetic treatment of geochemical cycles. Geochimica et Cosmochimica Acta, 44: 815-828.

Lasaga, A.C., 1981. Dynamic treatment of geochemica cycles: global kinetics. Reviews in Mineralogy, 8: 69-110.

Lasaga, A.C., Berner, R.A. and Garrels, R.M., 1985. An improved geochemical model of atmospheric $\mathrm{CO}_{2}$ fluctuations over the past 100 million years. In: Sundquist, E.T. and Broecker, W.S. (Editors), The Carbon Cycle and Atmospheric $\mathrm{CO}_{2}$ : Natural variations Archean to Present (Geophys Monogr., 32). Am. Geophys. Union, Washington, D.C., pp. $397-411$.

Lasaga, A.C., 1989. A New Approach to isotopic Modeling of the Variation Atmospheric Oxygen through the Phanerozoic. American Journal of Science, 289: 411-435.

Li,Y.-H. 1972. Geochemical mass balance among lithosfere, hidrosfere and atmosphere. American Journal of Science, 272,119-137

Mackenzie, F.T. and Morse, J.W., 1992. Sedimentary Carbonates through Phanerozoic Time. Geochimica et Cosmochimica Acta, 56: 3281-3295.

Mason, B.H. - 1971. Princípios de Geoquímica. São Paulo, Polígono, 381 pp. 
Nicolis, G. Et Prigogine, I. - 1992. À la Reecontre du Complexe paris, Presses Universitaires de France, $382 \mathrm{pp}$.

Raiswell, R. and Berner, R.A., 1985. Pyrite formation in euxinic and semi-euxinic sediments. American Journal of Science, 285: 710-724.

Raiswell, R. and Berner, R.A., 1986 Pyrite and organic matter in Phanerozoic normal marine shales. Geochimica et Cosmochimica Acta, 50:1967-1976.

Rice, J.R. (1993). Numerical Methods, Software and Analysis. New York, Academic Press, 720 pp.

Richardson, S.M. and McSween, H.Y., 1989. Geochemistry - Pathways and Process. Englewood Cliffs, Prentice Hall, 489 pp.

Sundquist, E.T., 1985. Geológical perspectives on carbon dioxide and the carbon cycle. In: Sundquist, E.T. and Broecker, W.S. (Editors), The Carbon Cycle and Atmospheric $\mathrm{CO}_{2}$ : Natural Variations Archean to Present (Geophys, Monogr. 32). Am. Geophys. Union, Washington, D.C., pp. 5-60.

Tardy, Y., 1987. Une introduction a la geochimie globale. Geochimica Brasiliensis, 1: 19. 39.

von Bertalanffy, L. 1968. General Systems Theory, George Braziller, New York, 289pp. 
APÊNDICES 
APÊNDICE A 
$1 \mathrm{C}$

2 C GALERI - MODELO DE ESTADO ESTACIONARIO

$3 \mathrm{C}$

4 C METODO DE ADAMS-MOULTON EXPLICITO - IVPAG

$5 \mathrm{C}$

6 C ENTRADA :

7 C FCN - SUBROTINA QUE AVALIA O SISTEMA

$8 \mathrm{C} X$ - VALOR INICIAL DA VARIAVEL INDEPENDENTE

$9 \mathrm{C} \mathrm{Y}$ - VETOR DAS VARIAVEIS DEPENDENTES

$10 \mathrm{C}$ IDO - INDICATIVO DO ESTADO DA COMPUTAÇÃO

$11 \mathrm{C}$ NEQ - NUMERO DE EQUAÇÕES DIFERENCIAIS

12 C XEND - SOLUÇÃO DE X

$13 \mathrm{C}$ TOL - TOLERANCIA DO ERRO

14 C PARAM - OPÇÕES DA BIBLIOTECA

$15 \mathrm{C}$

16 C SAIDA:

$17 \mathrm{C} X$ INTERPOLAÇÃO DADA POR XEND

$18 \mathrm{C}$ Y VETOR SOLUÇÃO DO SISTEMA

$19 \mathrm{C}$

$20 \mathrm{C} \mathrm{FL/FPc} \mathrm{GALER1.FOR/link} \mathrm{MATHCORE} \mathrm{BLAS} \mathrm{MATH5} \mathrm{MATH10/SE:500}$

$21 \mathrm{C}$

$22 \mathrm{CCCCCCCCCCCCCCCCCCCCCCCCCCCCCCCCCCCCCCCCCCCCCCCCCC}$

$23 \mathrm{C}$

24 IMPLICIT REAL*8 (A-H,O-Z)

25 IMPLICIT INTEGER (I-N)

$26 \mathrm{C}$

REAL*8 A(13,13),PARAM(NPARAM), \&TOL,X,XEND, Y(NEQ) EXTERNAL DFCN,DIVPAG,DSET,UMACH

HINIT $=1.0 \mathrm{D}-01$ INORM $=2$

IMETH $=1$

MITER $=0$

IATYPE $=0$

CALL DSET (NPARAM,0.0,PARAM,1)

$\operatorname{PARAM}(1)=$ HINIT

$\operatorname{PARAM}(10)=\mathrm{INORM}$

$\operatorname{PARAM}(12)=I M E T H$

PARAM(13)=MITER

PARAM(14)=MTYPE

PARAM(19)=IATYPE

$\mathrm{IDO}=1$

$\mathrm{X}=0$ 


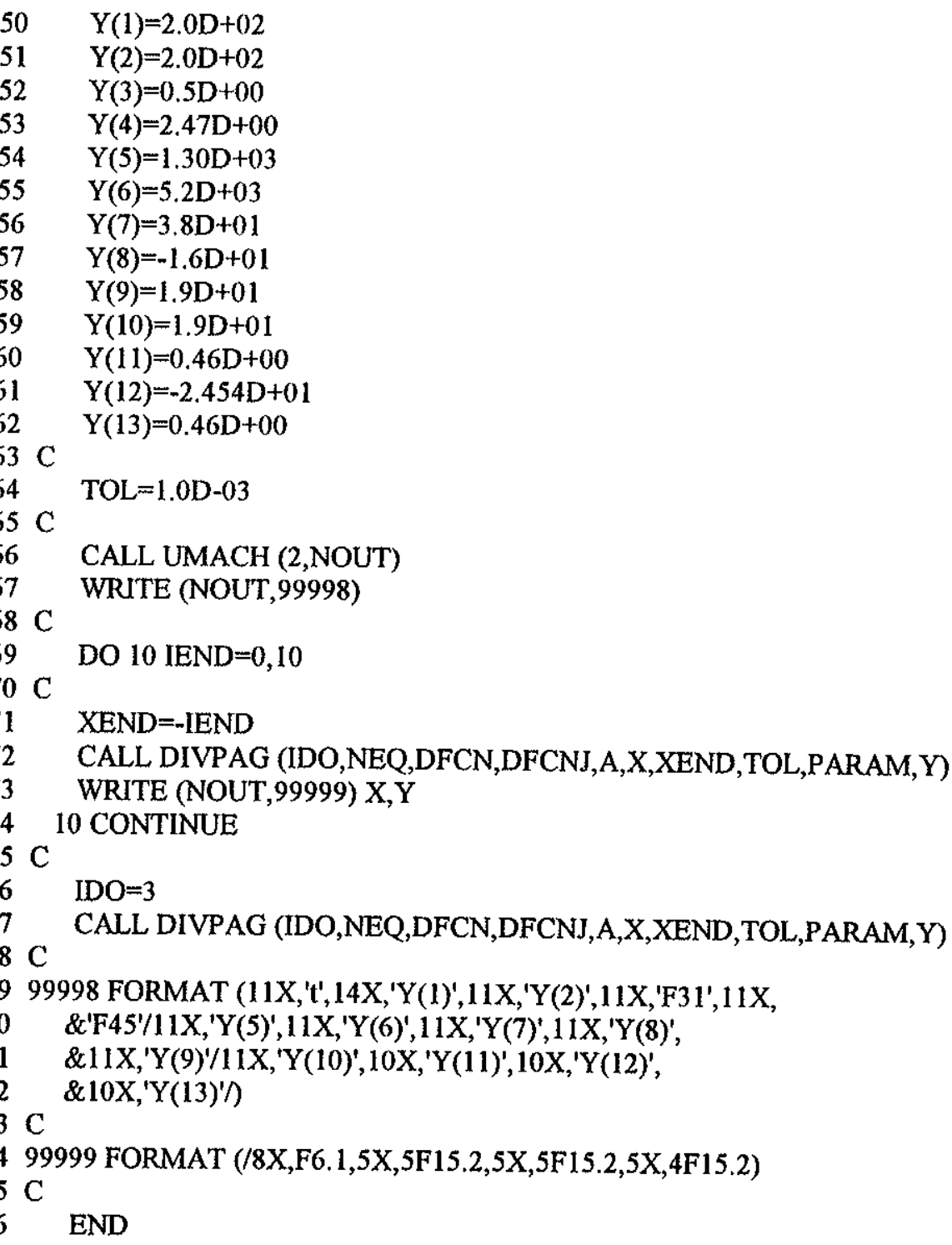




\begin{tabular}{|c|c|c|c|}
\hline IEND. . . . . . . . local & INTEGER*4 & 4 & $05 \mathrm{~d} 2$ \\
\hline DFCNJ . & REAL*8 & 8 & $05 \mathrm{~d} 6$ \\
\hline XEND. . & REAL*8 & 8 & 05de \\
\hline local & $\mathrm{REAL} * 8$ & 8 & $05 \mathrm{e} 6$ \\
\hline PARAM & $\mathrm{REAL} * 8$ & 400 & $05 \mathrm{ee}$ \\
\hline IMETH . & INTEGER*4 & 4 & $077 \mathrm{e}$ \\
\hline HINIT . & REAL*8 & 8 & 0782 \\
\hline Symbolic Constant & Type & Value & \\
\hline$\ldots \ldots$ INTE & $\mathrm{SER} * 4$ & 13 & \\
\hline NPARAM. . . . . . . INTEG & SER*4 & 50 & \\
\hline
\end{tabular}

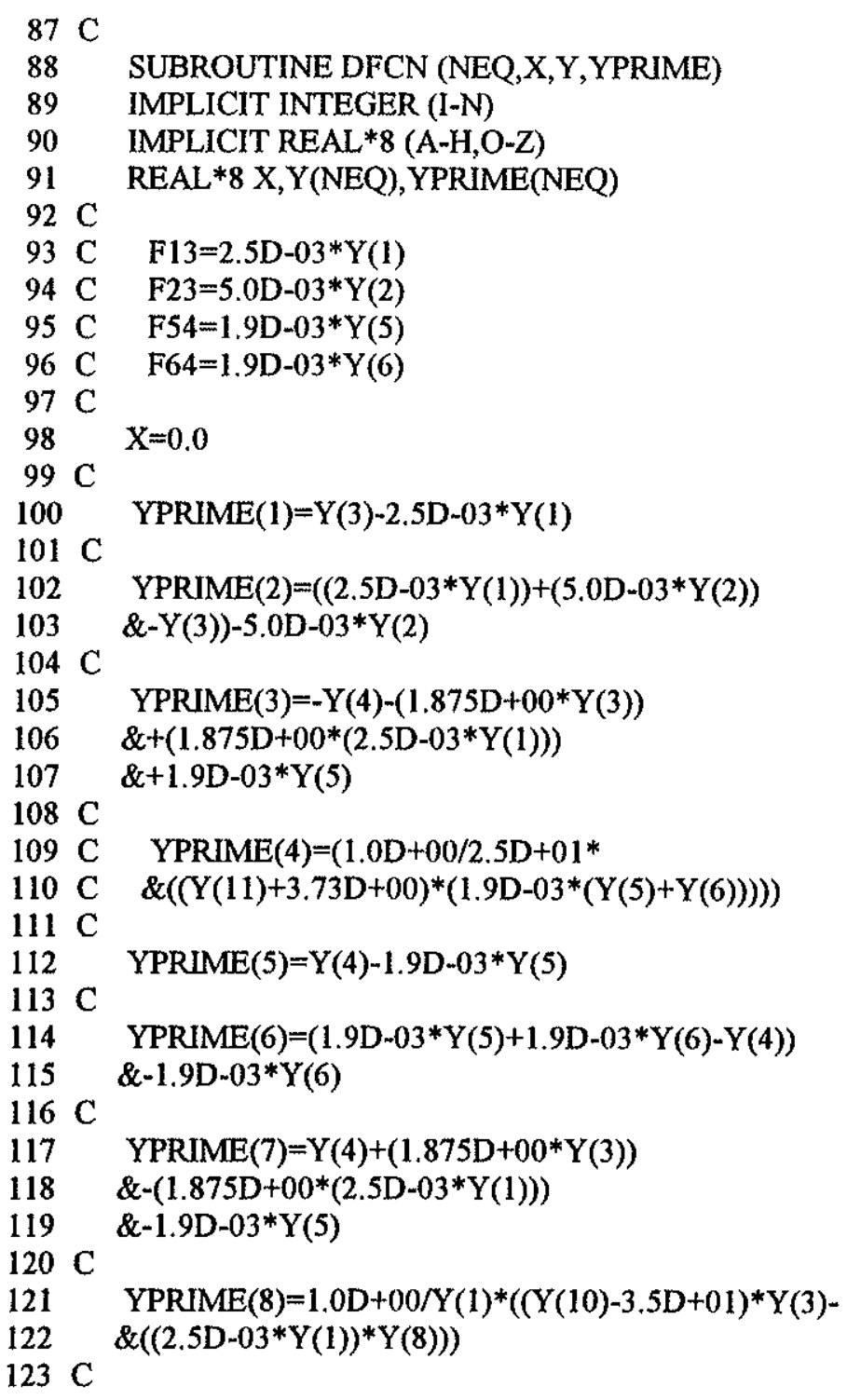




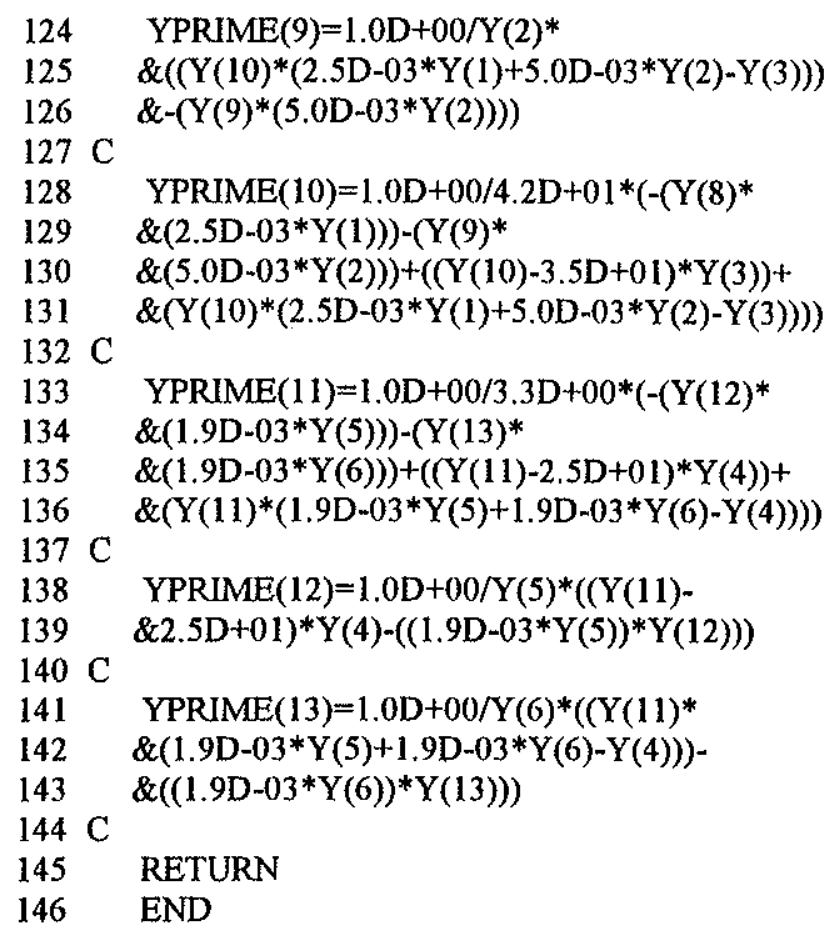

DFCN Local Symbols

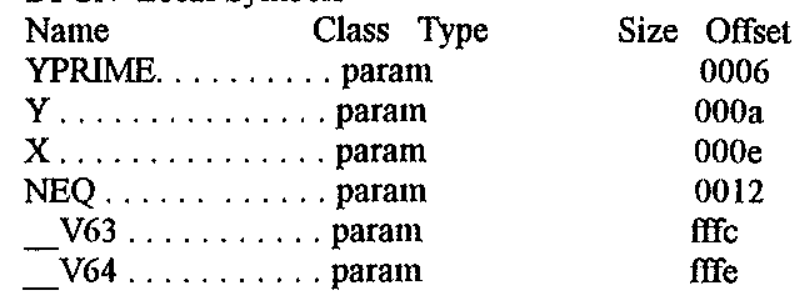

Global Symbols

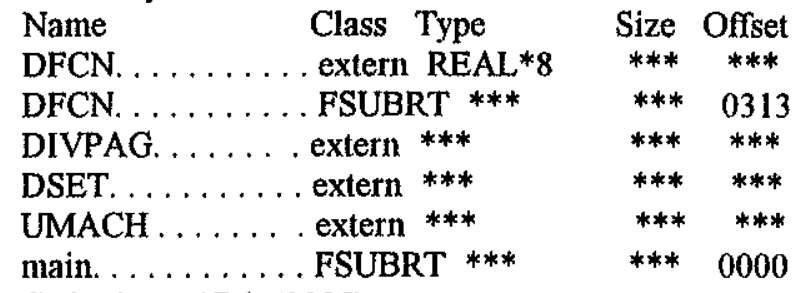

Code size $=07 \mathrm{cb}(1995)$

Data size $=00 \mathrm{db}(219)$

Bss size $=078 \mathrm{a}(1930)$

No errors detected 
APÊNDICE B 


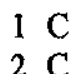

C - GALER2 - MODELO DE ESTADO NAO ESTACIONARIO

$3 \mathrm{C}$

4 C METODO DE ADAMS-MOULTON EXPLICITO - IVPAG

$5 \mathrm{C}$

6 C ENTRADA :

7 C FCN - SUBROTINA QUE AVALIA O SISTEMA

$8 \mathrm{C} X$ - VALOR INICIAL DA VARIAVEL INDEPENDENTE

$9 \mathrm{C} \quad \mathrm{Y}$ - VETOR DAS VARIAVEIS DEPENDENTES

$10 \mathrm{C}$ IDO - INDICATIVO DO ESTADO DA COMPUTAÇÃO

$11 \mathrm{C}$ NEQ - NUMERO DE EQUAÇÕES DIFERENCIAIS

12 C XEND - SOLUÇÃO DE X

$13 \mathrm{C}$ TOL - TOLERANCIA DO ERRO

14 C PARAM - OPÇÕES DA BIBLIOTECA

$15 \mathrm{C}$

16 C SAIDA :

$17 \mathrm{C} \mathrm{X}$ INTERPOLAÇÃO DADA POR XEND

$18 \mathrm{C}$ Y VETOR SOLUÇÃO DO SISTEMA

$19 \mathrm{C}$

$20 \mathrm{C}$ FL /FPc GALER2.FOR /link MATHCORE BLAS MATH5 MATH10/SE:700

$21 \mathrm{C}$

$22 \mathrm{CCCCCCCCCCCCCCCCCCCCCCCCCCCCCCCCCCCCCCCCCCCCCCCCCC}$

$23 \mathrm{C}$

24 IMPLICIT REAL*8 (A-H,O-Z)

25 IMPLICIT INTEGER (I-N)

$26 \mathrm{C}$

29 REAL*8 A(13,13),PARAM(NPARAM),

30 \&TOL,X,XEND, Y(NEQ)

HINIT $=1.0 \mathrm{D}-01$

INORM $=2$

IMETH $=1$

MITER $=0$

IATYPE $=0$

CALL DSET (NPARAM,0.0,PARAM,1)

PARAM(1) $=$ HINIT

$\operatorname{PARAM}(10)=$ INORM

PARAM(12)=IMETH

$\operatorname{PARAM}(13)=$ MITER

PARAM(14)=MTYPE

PARAM(19)=IATYPE

IDO $=1$

$\mathrm{X}=0$

$\mathrm{C}$ 


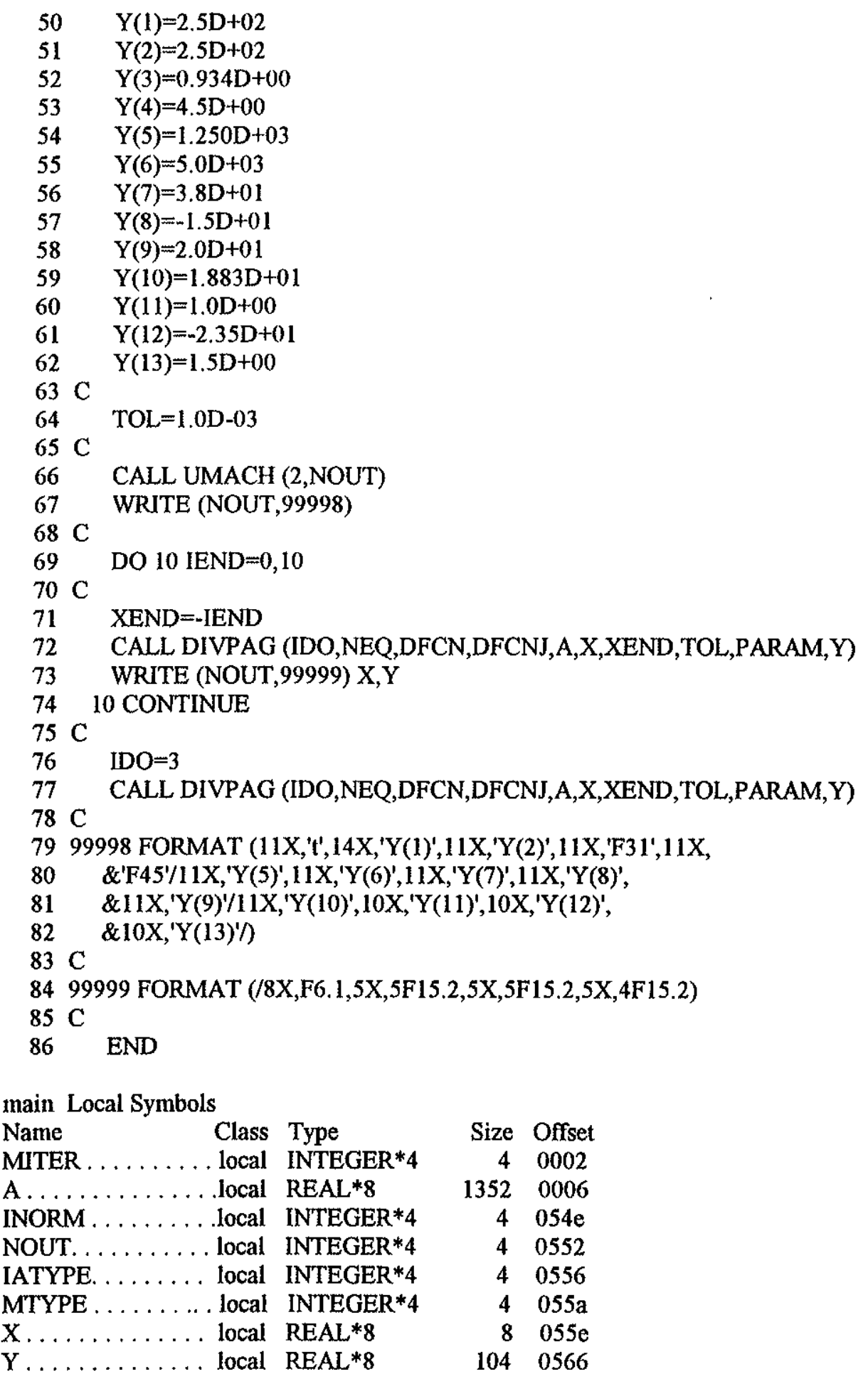




$\begin{array}{llll}\text { IDO } \ldots \ldots \ldots \ldots \text { local } & \text { INTEGER*4 } & 4 & 05 \mathrm{ce} \\ \text { IEND } \ldots \ldots \ldots \ldots \text { local } & \text { INTEGER*4 } & 4 & 05 \mathrm{~d} 2 \\ \text { DFCNJ } \ldots \ldots \ldots \ldots \text { local } & \text { REAL*8 } & 8 & 05 \mathrm{~d} 6 \\ \text { XEND } \ldots \ldots \ldots \ldots \text { local } & \text { REAL*8 } & 8 & 05 \mathrm{de} \\ \text { TOL } \ldots \ldots \ldots \ldots \text { local } & \text { REAL*8 } & 8 & 05 \mathrm{e} 6 \\ \text { PARAM } \ldots \ldots \ldots \ldots \text { local } & \text { REAL*8 } & 400 & 05 \mathrm{ee} \\ \text { IMETH } \ldots \ldots \ldots \ldots \text { local } & \text { INTEGER*4 } & 4 & 077 \mathrm{e} \\ \text { HINIT } \ldots \ldots \ldots \ldots \text { local } & \text { REAL*8 } & 8 & 0782\end{array}$

\begin{tabular}{|c|c|c|}
\hline lic Constant & Type & Value \\
\hline $\mathrm{NEQ}$ & INTEGER*4 & \\
\hline NPARAM. . . & INTEGER *4 & \\
\hline
\end{tabular}

$87 \mathrm{C}$

88 SUBROUTINE DFCN (NEQ,X,Y,YPRIME)

89 IMPLICIT INTEGER (I-N)

90 IMPLICIT REAL*8 $(\mathrm{A}-\mathrm{H}, \mathrm{O}-\mathrm{Z})$

91 REAL*8 X,Y(NEQ),YPRIME(NEQ)

$92 \mathrm{C}$

$93 \quad \mathrm{X}=0$

$94 \mathrm{C}$

95 YPRIME $(1)=\mathrm{Y}(3)-2.67 \mathrm{D}-03 * \mathrm{Y}(1)$

$96 \mathrm{C}$

97 YPRIME(2) $=((2.67 \mathrm{D}-03 * \mathrm{Y}(1))+(5.34 \mathrm{D}-03 * \mathrm{Y}(2))$

$98 \quad \&-Y(3))-5.34 \mathrm{D}-03 * \mathrm{Y}(2)$

$99 \mathrm{C}$

100 YPRIME(3) $=4.0 \mathrm{D}-03 * \mathrm{Y}(5)+(1.875 *(2.67 \mathrm{D}-03 * \mathrm{Y}(1)))$

$101 \&-\mathrm{Y}(4)-1.875 * \mathrm{Y}(3)$

$102 \mathrm{C}$

$103 \quad$ YPRIME(4) $=((1.0 \mathrm{D}+00 / 2.5 \mathrm{D}+01 *(\mathrm{Y}(11)+3.5 \mathrm{D}+00)) * 2.5 \mathrm{D}+01)$

$104 \quad \&-Y(4)$

$105 \mathrm{C}$

$106 \quad \mathrm{YPRIME}(5)=\mathrm{Y}(4)-4.0 \mathrm{D}-03 * \mathrm{Y}(5)$

$107 \mathrm{C}$

108 YPRIME(6) $=(4.0 \mathrm{D}-03 * \mathrm{Y}(5)+4.0 \mathrm{D}-03 * \mathrm{Y}(6)-\mathrm{Y}(4))$

$109 \&-4.0 \mathrm{D}-03 * \mathrm{Y}(6)$

$110 \mathrm{C}$

$111 \quad$ YPRIME (7) $=\mathrm{Y}(4)+(1.875 \mathrm{D}+00 * \mathrm{Y}(3))$

$112 \&-(1.875 \mathrm{D}+00 *(2.67 \mathrm{D}-03 * \mathrm{Y}(1)))$

$113 \&-4.0 \mathrm{D}-03 * \mathrm{Y}(5)$

$114 \mathrm{C}$

$115 \quad \mathrm{YPRIME}(8)=1.0 \mathrm{D}+00 / \mathrm{Y}(1) *((\mathrm{Y}(10)-3.5 \mathrm{D}+01) * \mathrm{Y}(3)-$

$116 \&((2.67 \mathrm{D}-05 * \mathrm{Y}(1)) * \mathrm{Y}(8)))$

$117 \mathrm{C}$

118 YPRIME(9) $=1.0 \mathrm{D}+00 / \mathrm{Y}(2)^{*}$

$119 \&((\mathrm{Y}(10) *(2.67 \mathrm{D}-03 * \mathrm{Y}(1)+5.34 \mathrm{D}-03 * \mathrm{Y}(2)-\mathrm{Y}(3)))$

$\left.120 \&-\left(\mathrm{Y}(9)^{*}\left(5.0 \mathrm{D}-03^{*} \mathrm{Y}(2)\right)\right)\right)$

$121 \mathrm{C}$

122

YPRIME $(10)=1.0 \mathrm{D}+00 / 3.8 \mathrm{D}+01 *(-(\mathrm{Y}(8) *$ 


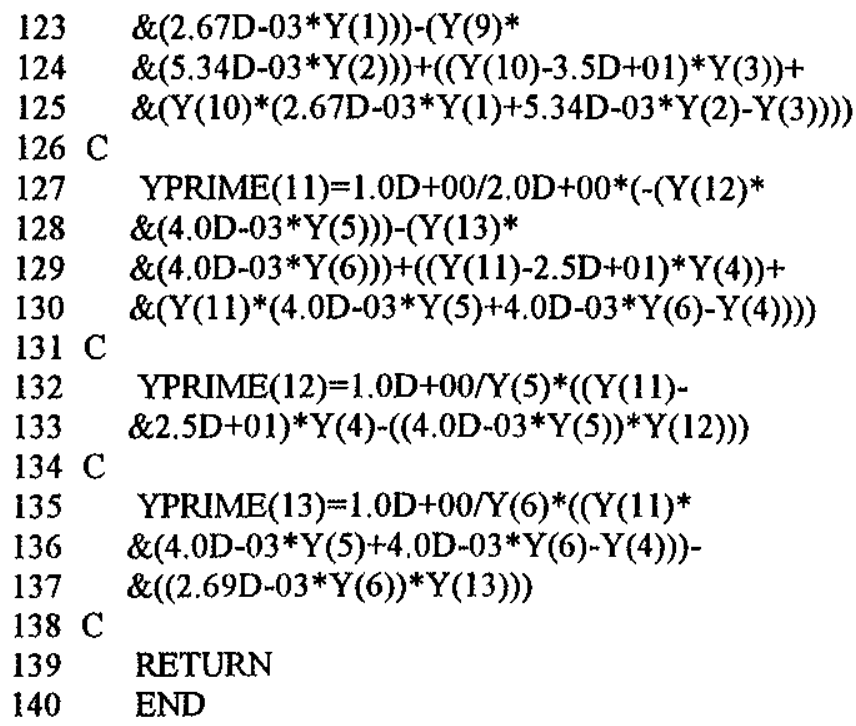

DFCN Local Symbols

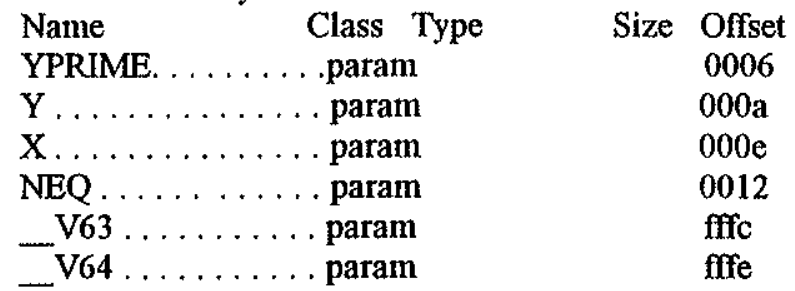

Global Symbols

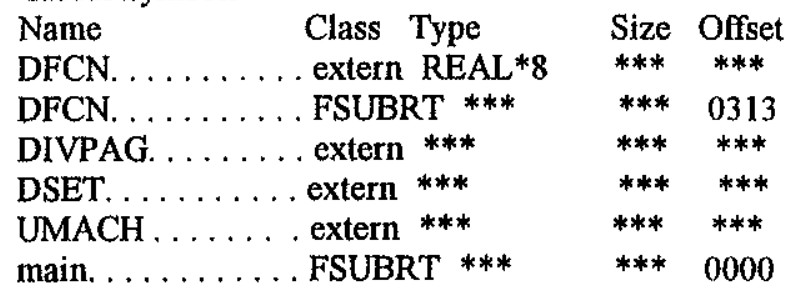

Code size $=081 \mathrm{e}(2078)$

Data size $=010 \mathrm{~b}(267)$

Bss size $=078 \mathrm{a}(1930)$

No errors detected 
APÊNDICE C 
$1 \mathrm{C}$

2 C - GALER3 - MODELO PARA ESTADO NAO-ESTACIONARIO

$3 \mathrm{C}$

4 C METODO DE RUNGE-KUTTA - IVPRK

$5 \mathrm{C}$

6 C ENTRADA :

7 C FCN - SUBROTINA QUE AVALIA O SISTEMA

$8 \mathrm{C} X$ - VALOR INICIAL DA VARIAVEL INDEPENDENTE

$9 \mathrm{C} \mathrm{Y}$ - VETOR DAS VARIAVEIS DEPENDENTES

$10 \mathrm{C}$ IDO - INDICATIVO DO ESTADO DA COMPUTAÇ̃̃O

11 C NEQ - NUMERO DE EQUAÇÕES DIFERENCIAIS

12 C XEND - SOLUÇÃO DE X

$13 \mathrm{C}$ TOL - TOLERANCIA DO ERRO

14 C PARAM - OPÇÕES DA BIBLIOTECA

$15 \mathrm{C}$

16 C SAIDA:

$17 \mathrm{C} X$ INTERPOLAÇÃO DADA POR XEND

$18 \mathrm{C} \quad \mathrm{Y}$ VETOR SOLUÇÃO DO SISTEMA

$19 \mathrm{C}$

20 C FL/FPc GALER3.FOR /link MATHCORE BLAS MATH5 MATH10/SE:500

$21 \mathrm{C}$

$22 \mathrm{CCCCCCCCCCCCCCCCCCCCCCCCCCCCCCCCCCCCCCCCCCCCCC}$

$23 \mathrm{C}$

INTEGER NEQ,MXPARM

PARAMETER $(\mathrm{NEQ}=13, \mathrm{MXPARM}=50)$

INTEGER IDO,ISTEP,NOUT

REAL FCN,PARAM(MXPARM),TOL,T,TEND, Y(NEQ),FLOAT

EXTERNAL FCN,IVPRK,SSET,UMACH

$1 \mathrm{C}$

CALL UMACH $(2$, NOUT)

$$
\mathrm{T}=0.0
$$

$$
\mathrm{Y}(1)=2.5 \mathrm{E}+02
$$

$Y(2)=2.5 E+02$

$\mathrm{Y}(3)=0.934 \mathrm{E}+00$

$\mathrm{Y}(4)=4.5 \mathrm{E}+00$

$Y(5)=1.250 \mathrm{E}+03$

$\mathrm{Y}(6)=5.0 \mathrm{E}+03$

$Y(7)=3.8 \mathrm{E}+01$

$Y(8)=-1.5 \mathrm{E}+01$

$Y(9)=2.0 \mathrm{E}+01$

$Y(10)=1.883 \mathrm{E}+01$

$\mathrm{Y}(11)=1.0 \mathrm{~B}+00$

$Y(12)=-2.35 \mathrm{E}+01$

$\mathrm{Y}(13)=1.5 \mathrm{E}+00$ 


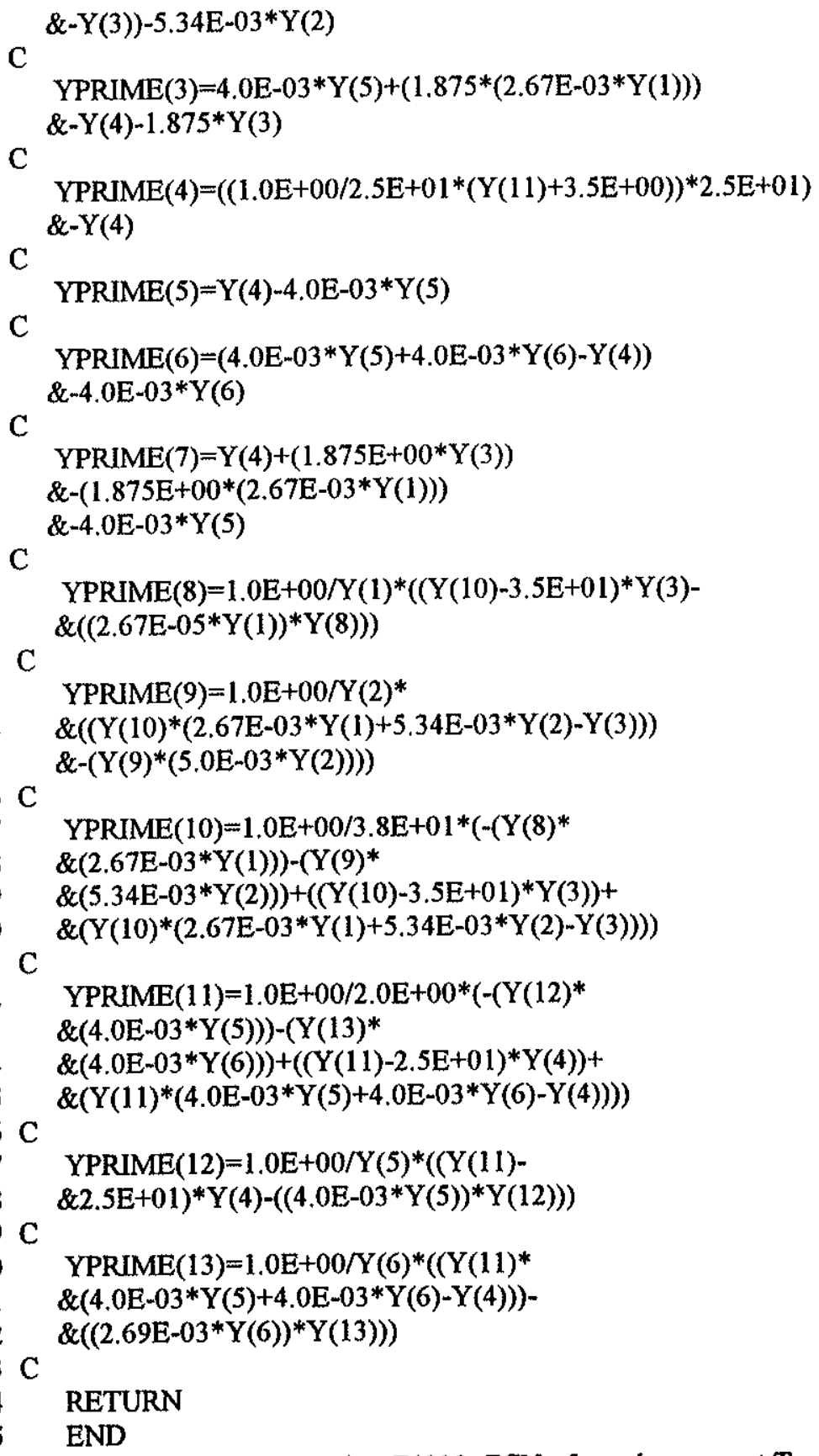

FCN Local Symbols

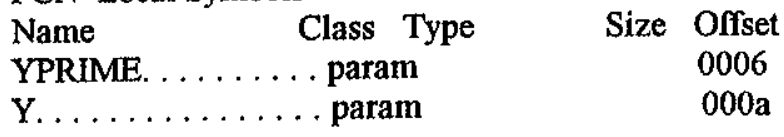


Microsoft FORTRAN Optimizing Compiler Version 4.01

\begin{tabular}{ll}
$\mathrm{T} \ldots \ldots \ldots \ldots \ldots$ param & $000 \mathrm{e}$ \\
$\mathrm{NEQ} \ldots \ldots \ldots$ param & 0012 \\
V $56 \ldots \ldots \ldots$ param & $\mathrm{fffc}$ \\
\hline $\mathrm{V} 57 \ldots \ldots \ldots$ param & $\mathrm{ffre}$
\end{tabular}

\section{Global Symbols}

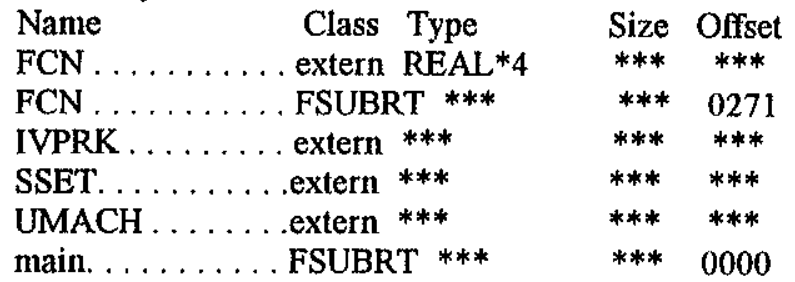

Code size $=0764(1892)$

Data size $=008 \mathrm{f}(143)$

Bss size $=0116(278)$

No errors detected 